\title{
Development of a Prosodic Read Speech Syllabic Corpus of the Yoruba Language
}

\author{
Akintoba Emmanuel Akinwonmi \\ Department of Computer Science \\ The Federal University of Technology, Akure \\ Ondo State, Nigeria
}

\begin{abstract}
Literature revealed that the need for annotated database of speech text or audio files is justified primarily by the requirements for corporal entities to conduct basic Natural Language Processing (NLP) studies on a language. Such investigationstraverse thephonetic, aural and etymological representations of the language. Moreover, research of interest can also span grammatic, semantic, pragmatic and syntactic characterizations of the particular language. At a secondary level an annotated speech corpus is desirable for the purpose of speech synthesistypified by Text-to-Speech (TTS) and recognitionas in Speech-to-Text (STT). Yoruba language, a resource scarce language with a wide usage, has sparse andscarce digital resources and its computerization poses unique challenges. Annotated speech corpus is one of such resources. Hence, this research was motivated by the need to contribute to the scanty resources for the language. This research minedtextual inputs from four sources including two Standard Yoruba (SY) fiction, an SY grammar textbook and an SY Online Scripture. A hybrid of Falaschi scheme and the add-on procedure of Radová and Vopálka were applied to extractphonetically balanced text bag of 7376 phrases and sentences with a view to minimizing the extraction cost, while maximizing phonetic coverage of all standard Yoruba syllabic events. The selected text was read by an expert and recorded in a suitable environment and saved as wave files. The wave files were annotated with Praat. A relational database was developed to host the corpus metadata. The corpus performed impressively when tested with a Standard Yoruba TTS. This paper presents the design, implementation, results and other useful information about the research.
\end{abstract}

\section{General Terms}

Speech Processing, Natural Language Processing, Resource Scarce language Processing, Yoruba Language processing

\section{Keywords}

Speech, Corpus, Yoruba Language, chunk, Syllabification

\section{INTRODUCTION}

The Yorùbá language is natively spoken by around 22 million people. It is one of the four major African spoken languages and one of the three major local languages together with English in Nigeria. Standard Yorùbá (SY) is a member of the dialect group used in written Yorùbá in schools and spoken by newsreaders. A speech corpus may primarily support researches at establishing differences between speakers, such as gender, age, environment, speech quality and channels of data. These factors control the speech specificity. Thus, a speech corpus is indispensable in speech processing. It is actually a veritable research material in speech paradigm.
A speech database is essential in the development of systems that support speech processing, synthesis and speech recognition. Thus, fashioning an efficient schema, management protocol, organization, flexibility and monitoring the size of the database is key to have qualitative data-driven speech processing systems. Hence, in designing a speech corpus, the scope of coverage of the language structure (speech units, syntax, word order and grammar) and its phonetic aspect is critical [21].

\section{THE YORÙBÁ LANGUAGE}

Yorùbá belongs to the Kwa language subgroup of the NigerCongo languages phylum [1]. It seems that the language has a moderate diaspora. However, its diaspora is wide. It stretches from southwestern Nigeria to Central Togo, East Central part of Republic of Benin, Sierra Leone (Aku variant) to the Caribbean and covering some other islands along the southeastern United States coast. All through the area, the dialects intermix with each other, with Spanish and French forming Gullah variant in the U.S.A and Nagô variant in Brazil. Many slaves brought to North America during the 18th and 19th centuries were of Yorùbá -speaking origin [2].

The language is natively spoken by around 22 million people.It is one of the four major African spoken languages and one of the three major local languages together with English in Nigeria. The highest concentration of its global speakers is in Lagos, Oyo, Ogun, Ondo, Ekiti, Osun, Kwara some part of Edo, and Kogi states in Nigeria. As reported in [3], Yoruba dialect groups include:

a. North-West Yoruba (NWY). Spoken in Abẹokuta, Ibadan, Oyọ, Ogun and Lagos (Eko) areas

b. Central Yoruba (CY) Spoken in Igbomina, Yagba, Ifẹ, Ekiti, Iworoko Ekiti, Akurẹ, Ẹfọn, and Ijẹbu areas.

c. South-East Yoruba (SEY) Spoken in Okitipupa, Ondo, Ọwọ, Ikare, Sagamu, and parts of Ijẹbu.

\subsection{Yorùbá Phonology}

Standard Yorùbá (SY) is a member of the dialect group used in written Yorùbá in schools and spoken by newsreaders. It originated in the 1850s after [4]. Though, it is largely based on the Oyo and Ibadan dialects, it incorporates several features from other dialects [5].

Segmental phonology of Yorùbá alphabets includes seven vowels (a, e, e, i, o, o, u), 18 consonants (b, d, f, g, gb, h, j, k, $1, \mathrm{~m}, \mathrm{n}, \mathrm{p}, \mathrm{r}, \mathrm{s}, \mathrm{s}, \mathrm{t}, \mathrm{w}, \mathrm{y}$ ) and 5 nasalized vowel phonemes (an, ẹn, in, ọn, un). Yorùbá is tonal (accented) with 3 contrastive tones and 2 allotones. The Yoruba letters without diacritics resemble the International Phonetic Alphabet equivalents in 
pronunciation. It differs on the labial-velarstops $[\widehat{\mathrm{kp}}](\langle\mathrm{p}\rangle)$ and $[\widehat{g b}](\langle\mathrm{gb}\rangle)$. Both consonants are pronounced concurrently.

Moreover, the glyph underneath vowels in open vowels constricts pronunciation with 〈ẹ pronounced as [ع]

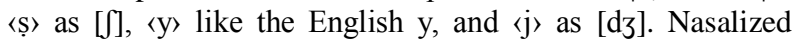
vowels are specified as oral vowels followed by " $n$ ".

\subsection{Tone and Intonation in Yorùbá}

Tonal configurations ofYoruba alphabets are the following:

A, a, Á, á, À, à, B, b, C, c, Ç, ç, D, d, E, e, É, é, È, è, Ê, ê, Ë, ë, F, f, Gb, gb, G, g, H, h, I, I, Í, í, İ, ì, J, j, K, k, L, l, M, m, N, n, O, o, Ó, ó, Ò, ò, Ô, ô, Ö, ö, Õ, õ, P, p, R, r, S, s, B, ÿ, T, t, ${ }^{a}$, P, p, Ý, ý, U, Ú, ú, Ù, ù, W, w, Y, y

Three diacritics that are used on vowels and syllabic nasal consonants depict tones. The language allows more than one tone per syllable. The following different syllabic vowel forms are acceptable:

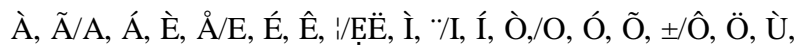
$\varnothing / \mathrm{U}, \mathrm{U}$

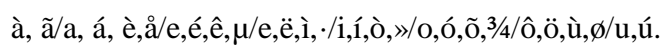

In SY, syllabic tones differentiate words of identical segmental phonemes. There are three tonal phonemes H(igh), M(id), and L(ow) [4] Corresponding to an acute accent '’, optional macron \langle\rangle and grave accent \langle\rangle . $H$ tone occurs in word-initial position only in marked consonant-initial words. The following monosyllables can have different meanings as shown:

\section{di: dí (H) to block; dì (L) to pack/tie and dī (M) be deafened}

Disyllabic tonal strings in Yoruba give: HH, HM, HL, MH, MM, ML, LH, LM, LL, a total of Tx configurations from T tones and $\mathrm{x}$ syllables with less than these number of acceptable (meaningful) configurations in most words [6]. Others are rather nonsensical as this type of parsing only considers syntactic factors; semantics is completely ignored.

Table 1. Tonal Configuration of Disyllabic Yoruba Words

\begin{tabular}{|c|c|c|c|c|c|c|}
\hline$\stackrel{\ddot{E}}{\Xi}$ & $\overrightarrow{0}$ & 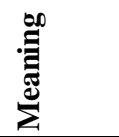 & jo & 晜 & : & 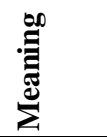 \\
\hline MH & āyé & World & īyá & a plant & ęgbá & $*$ \\
\hline MM & $\overline{\text { Āyè }}$ & A Town & $\overline{1} y \bar{a}$ & $*$ & ẹgbā & cudgel \\
\hline ML & Ayè & A Town & îyà & $*$ & ẹgbà & $*$ \\
\hline $\mathrm{HH}$ & Áyé & $*$ & Íyá & $*$ & égbá & $*$ \\
\hline HM & áyē & $*$ & íyā & $*$ & égbā & $*$ \\
\hline $\mathrm{HL}$ & Áyè & $*$ & Íyà & $*$ & égbà & $*$ \\
\hline LL & Àyè & Space & İyà & Penance & ègbà & Bangle \\
\hline $\mathrm{LH}$ & Àyé & $*$ & İyá & Mother & Ėgbá & A Tribe \\
\hline $\mathrm{LM}$ & àyē & $*$ & ìyā & $*$ & ègbā & $*$ \\
\hline
\end{tabular}

* Unattested

Most words start with a vowel, which is Low or Mid but not High. In SY, tones occur freely in lexical representations, without apparent restrictions on word melodies [1].So, there are 3 possible tonal patterns for monosyllables, 9 patterns for disyllables, and so on. Moreover, in Yorùbá and other syllable-timed languages such as Spanish, Greek, French, Italian, and Telegu, syllables are periodic and often end with a vowel. Whereas in stress-timed languages such as English, Arabic, Russian, and Thai syllable, stress recur approximately periodically and most syllables end with a consonant. Tone in Yorùbá language has been adequately researched and well documented [7][8]. However, the distinctive intonation system due to Yoruba tones continues to be inadequately researched. To this, [9] reasoned that the distraction of linguists' attention from the suprasegmental features of intonation by the impetus on the semantic role of tone is partly responsible for the trend. In spite of advances made in investigating the prosodic features of major world languages, Yoruba has not received adequate research.

\subsection{Prosody in Speech}

In speech, the acoustic changes in frequency, amplitude, and duration that form grouping, prominence, and intonation are called "prosody"; these features are systematically derived within each language and are thought to be rule-governed and distinct from other structural levels of linguistic analysis [10].

The role of prosody in natural speech is very crucial. The resultant effect of the variations in speech parameters that is specified by changes in duration, pitch and loudness of speech units is perceived as prosody. In synthetic speech, the prosody must be made as similar as possible to that of the natural in order to have a high level of speech intelligibility and naturalness.

Prosody is responsible for the major part of the intelligibility and naturalness of spoken sentences. Syntactic, semantic, as well as emotional information are all conveyed via prosody. Prosodic aspects are often divided into features such as in English stress and intonation. Prosody is in short can be described as the "music" of speech [11].

\subsection{Nature of Yoruba Prosody}

Different approaches have been used for generate Yoruba prosody ranging from the use of some simple rules to the use of statistical approaches. Such statistical approaches include artificial neural networks, CART, probabilistic approach and hybrid methods. Yoruba is a syllable-based tonal language as such its prosody is characterized by the following properties:

a. Each Yoruba character is pronounced as a syllable.

b. There is a neutral tone called middle tone, a low and a high typical tone. Similar simple syllable types carry different functional meanings if they have dissimilar tones.

c. In terms of prosody, an utterance segments into minor prosodic units including words, minor phrase, and intonation phrase.

d. Each syllable of a Yoruba utterance has a tonal individuality while the utterance exhibits a global intonation.

Considering the foregoing, Yoruba pitch contour has two parts: a restricted component for tone and an overall component for the utterance's general intonation. Thus, the final pitch contour of an utterance is an outcome of the resultant effect of the two components.

\subsection{Text Decoding}

Text decoding in Text-To-Speech (TTS) is a classical disambiguation problem which entails the determination of the only one correct sequence of words which gave rise to the text sequence of words in a tokenized text. With numbers, 
dates, named entities and other non-natural language text there may be a few diverse appropriate word chains. Text coding disambiguates such different word chains. With regards to a well performed part-of-speech (POS) tagging, the English words: read, present, record each can have two different pronunciations, and so this is the type of ambiguity needing resolution. Another case is how resolve ambiguity of the language's verbal component, for example, knowing whether 2021 is a number or a year. Resolving this involves: determining the semiotic class for each word or token; resolve any ambiguity for each chain of word/tokens in each semiotic class, then derive their underlying forms and convert each non-natural language classes (dates, numbers and named entities, cardinal numbers, ordinal numbers, telephone numbers, money, percentages and measures) into correct verbalization sequence.

In general, words with alternative spellings, abbreviations, unknown words, homographs (accidental homographs, partof-speech homographs and abbreviation homographs) and mis-spellings require a sophisticated text decoding models to handle. However, this research will be limited to developing a prosodic TTS for natural language texts. Fair enough, [12] showed that the orthography of SY was shallow. Thus, synthesizing speech from Yorùbá text may not need complicated syntactic analysis. Unambiguous diacritical characterization in SY orthography clearly eradicates the vagueness in pronunciation of otherwise synthetically clumsy words thus a POS algorithm as in [13]is not necessary.

\subsection{The Need forSyllabification}

[23] categorized Yoruba as a resource-scarce language. A Resource-scarce language is one which has scarce or few digital resources and its computerization poses unique challenges. These challengesinclude unavailability of electronic lexica, standardized electronic corpus and tools such as Part-of-Speech (POS) tagger, phonetiser, syllabificator and optical character Recognition (OCR) tool. It also includes the lack of the political and the financial strength to cause developers and decision-makers in the computer industry to give attention to the needs of the language.

Computerization of Yoruba is more compounded by the absence of basic text processing tool like a well-suited Yoruba keyboard and optical character recognition (OCR) in spite of its large language sphere. Optical character recognition is a technology that enables the conversion of different types of documents such as scanned paper document, PDF files or images captured by a digital camera into editable and searchable data. Availability of which will ease the initial process of text acquisition for computational or research purpose.

A vital challenge encountered when developing an automated syllabificator for TTS system or a speech synthesis system is posed by the need to build a proper speech corpus for the necessary system training and testing. The main hurdles to cross in doing these involve the need to decide the source of materials and the conversion of the text materials into editable form. The last can be solved in two steps by selecting a set of appropriate sentences from a suitable text source. Thereafter, the selected sentences will be broken into syllables and error encountered as a result of text conversion by the scanner, can be manually corrected.

\subsubsection{Application of Language Syllabificator A language syllabificator provides grammarians,}

lexicographers, Natural language processing (NLP) experts and other interested parties with better descriptions of a language. It plays a crucial role in automatic speech recognition, text-to-speech systems, and corpus statistics.

\subsubsection{Advantages of Using A Language Syllabificator}

The syllabified texts in the corpus are time and money saving with access to a much larger corpus than a single individual researcher could construct. A further advantage to working with a corpus in the public domain is the possibility of building on the work others have done using the same corpus or using prior results as a benchmark for testing new research methods.

\subsection{YorubaOK Font}

This font is aimed at promoting the reading, speaking and writing of the Yoruba language properly. It is complete with all the required intonation and diacritic marks of Yoruba language. It was developed by Mr. James Kass and this development has enabled the typing of Yoruba text properly. YorubaOK Font has a File size of $3375 \mathrm{~kb}$. It can work on operating systems like windows XP/Vista/7/8. It is a free source and can be downloaded online [13]. The only way to write Yoruba without any limitations and with universal compatibility is for the proprietary fonts used to conform to the UNICODE standard for Yoruba text. It makes it possible for users to acquire and install a capable file that will then work like a standard font e.g. Arial, Courier or Times New [13].

\section{REVIEW OF RELATED RESEARCHES ON STANDARD YORUBA NLP RESOURCES}

[14] developed Text Statistics Tool Box that attempted among other tasks to count the number of syllables in a characteristic list (that is a sentence) using English syllable rules. The rules utilized in constructing this toolbox made accuracy difficult as the system can easily misclassified syllables. Another set of efforts at counting the syllables in an English sentence were also made. None of these is guaranteed to give very good results and none was designed with the intent of producing tokens.

The OAK System was developed by the Proteus Project of the Department of Computer Science of the New York University as a "total analyzer for English". The tokenizer tokenizes into words or word forms but not into syllables. The tokenizer in the Stanford Natural Language Processing (NLP) Toolbox of the Stanford NLP Group also tokenize into words and word forms. The English language tokenizer is a Finite State Machine tokenizer based on hand-written rules. The Open NLP tools are a set of Java-based NLP tools that perform sentence detection and tokenization among other tasks for two European languages and one Asian language. The tokenizer which is for tokenizing sentences into words followed the token style for the English Penn-Treebank. NL Tokenizer for English Language tokenizes a text into paragraph, sentences, words (including simple word-form, abbreviations and numbers) that can work in standalone mode or as part of another module.

[15] is closely related to this work. The authors developed a Swahili Text-To-Speech application that has a syllabification module (SM) embedded. The SM takes in a text consisting of strings of Swahili words and output string of syllables to be 
fed as input into a Digital Signal Processor that synthesizes the speech also used a rule-set however simpler due to the simpler syllable structure of Swahili.

[16] reported on the development of a syllabicator for Yoruba language. "Syllabicator" is a synonym for "Syllabificator". Their work was motivated by the need to contribute to NLP resources for Yoruba language. They identified a syllabicator as one of the needed research resources for Yoruba as a tonal language. The authors used a declarative rule-based approach for the syllabification of Yorùbá words. The declarative rulebased approach is one in which just one rule that is first deterministically applicable is selected while others are ignored as they do not apply to the given situation. Their method initially determined the length of the selected word from a sentence and thereafter applied a set of rules that takes into consideration the characters in the word and the order or arrangement of the characters within the word as defined by Yoruba orthography. Thereafter the researchers applied 23 rules that were categorized into 4 cases to determine syllable boundaries. Though an evaluated performance of $99.993 \%$ accuracy of returning correct syllables from a given word when evaluated on a text size of 90622 words was reported, their system lacks the ability to discriminate against nonYoruba words. Moreover, some words containing DVn and CVn, especially name identities must be treated specifically. For instance, while their system would syllabify Igbin correctly as I. gbin (2 syllables), Bankole should be syllabified as Ba.n.ko. le (4 syllables) not Ban.ko. le (3 syllables). Ditto for Banke, Banro, kengbe, and other similar SY words as would be the case. Several examples of such Yoruba words exist.

[17] proposed a prosody realization in Text-to-Speech (TTS) applications for Yoruba language. Their work was motivated by the need contribute NLP research tools to Yoruba Language. The objectives of their research were to model prosody from the speech of a Yoruba language speaker and also to develop a Hidden Markov Model (HMM) based TTS system for Yoruba text. Although their proposal underscored the prominence and indispensable of language corpora in Natural Language processing, one major challenge emphasized in their work was in the development of a speech corpus of Yoruba language. In overcoming this challenge an accurate, language specific OCR and Syllabificator is inevitable.

[18] presented Part-of-Speech tagging of Yoruba Standard; Language of Niger-Congo family. Their work was motivated by the need to obtain training data for part of speech taggers and to contribute basic application resources towards Yoruba Language Processing. Their paper aimed to design a Yoruba corpus. The tagging was performed with Support Vector Machine Tool one of the Part-of-Speech taggers widely used. The corpus with 312,562 words, formed from the Web, was annotated with an accuracy of $98.04 \%$. This annotated corpus might be used in translation system. First, the researchers made the choice of tools and then moved on to the Part of Speech Tagging. The first tool of their work is Yoruba language. The authors classified Yoruba as a tonal language which has three tones: high tone (represented by the acute accent), the low tone (represented by the grave accent) and the average tone (represented by the absence of accent). They first performed the text pre-processing (segmentation, removing duplicates) using scripts written in Perl (Perl 5) before performing part of Speech tagging. The researchers considered Part of Speech Taggers as Natural Language
Processing tools that are neutral, because they are able to adapt to any language, as long as the corpus and models are available. They used machine learning methods. These methods allow in the first time, to learn the language based on some relevant examples of sentences which are provided. The main result of their research is the creation of the annotated corpus with Part of Speech Tagging for the Yoruba. Moreover, they based their research on a somewhat contestable premise that, Yoruba had a unique alphabet containing thirty (30) letters composed of 12 vowels: i, e, e , a, o, o, u, in, ẹn, ọn, un, an and 18 consonants: $b, d, f, g, g b, h, j$, $\mathrm{k}, \mathrm{l}, \mathrm{m}, \mathrm{n}, \mathrm{p}, \mathrm{r}, \mathrm{s}, \mathrm{s}, \mathrm{t}, \mathrm{w}, \mathrm{y}$. The result of their research cannot be safely applicable to SY because truly'in', 'ẹn', 'ọn', 'un', and 'an' are not considered as alphabets in Standard Yoruba.

[19] improved on the model of [16]by introducing a language filter made up of a regex (wild character structure) filter pass and/or word-list pass which allowed the system to discriminate against non-Yoruba words. However, the underlying rules and design became more complex even as the system would still not be able to handle some words containing DVn and CVn, especially name identities that must be treated specifically (Bankole would still be wrongly returned as Ban.ko.le - 3 syllables).

\section{SYSTEM DESIGN}

Concatenate synthesis and formant synthesis are the predominantly used approaches for producing speech waveforms. The choice of which of the technologies to use depends on the intended uses of a synthesis. They both have varying strengths and weaknesses. This research applies the concatenate-synthesis-based unit selection using syllables as the base units.

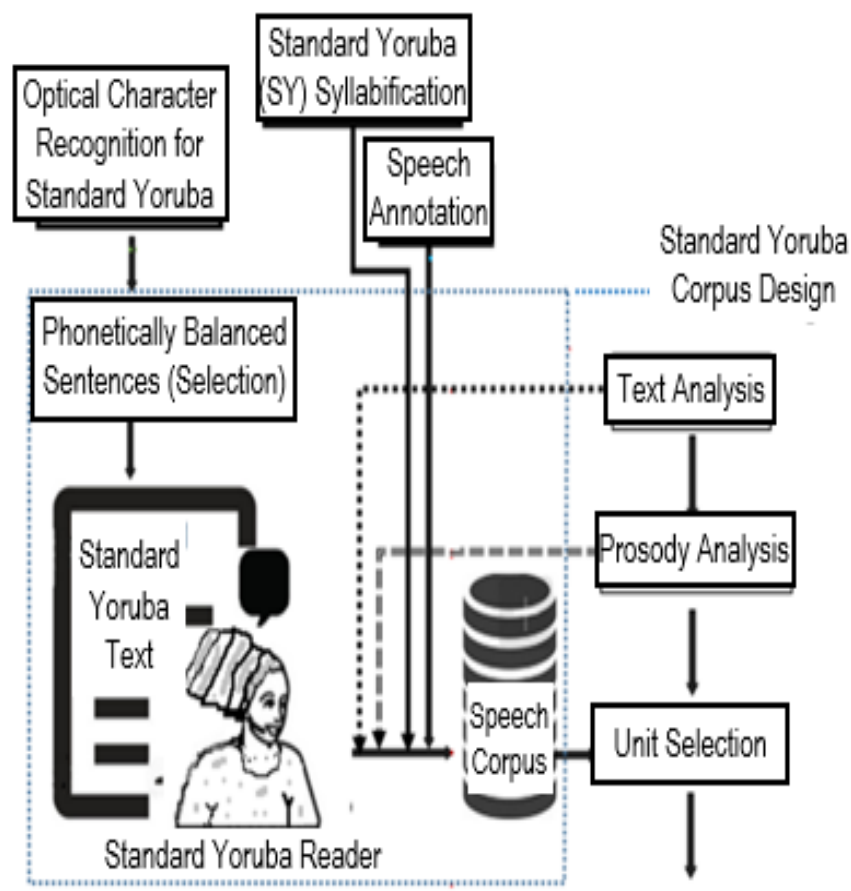

Figure 1: Standard Yoruba Corpus Design 


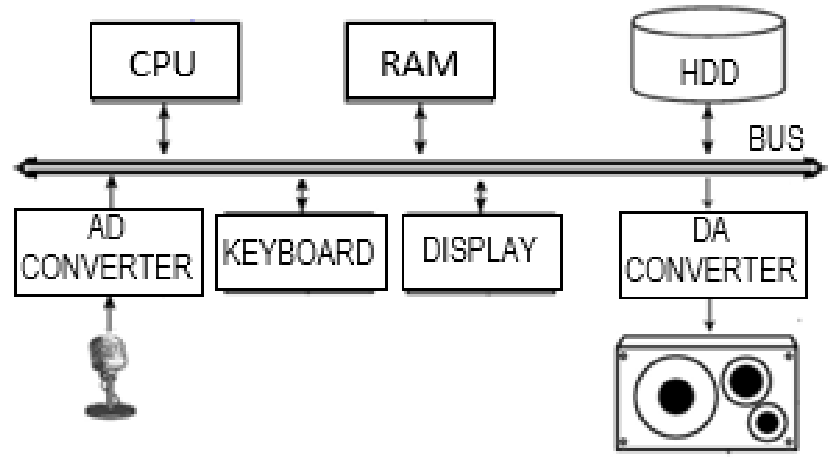

Figure 2: A block diagram of hardware support for Standard Yoruba Corpus

\subsection{Design of the SY Read Speech Corpus}

The need for a read speech database is justified firstly by the requirements for corporal entities to conduct basic research on a language as posited by [20]. These can span the auditory, phonetic, etymological, semantic, syntactic representations of the particular language. This factor concerns the design of the database: it also affects the response time in speech systems. Moreover, a speech corpus may primarily support researches at establishing differences between speakers, such as gender, age, environment, speech quality and channels of data. These factors control the speech specificity. Thus, a speech corpus is indispensable in speech processing. It is actually a veritable research material in speech paradigm. A speech database is essential in the development of systems that support speech processing, synthesis and speech recognition. Thus, fashioning an efficient schema, management protocol, organization, flexibility and monitoring the size of the database is key to have qualitative data-driven speech processing systems. Hence, in designing a speech corpus, the scope of coverage of the language structure (speech units, syntax, word order and grammar) and its phonetic aspect is critical [21].

\subsection{Read Text Corpus Database}

This subsection presents the design of the relational schema of the corpus database, built on a conceptual schema design. The
Extended Entity-Relationship modeling tool is used to derive the design as shown in Figure 3. The resulting relational database structure is shown in Figure 4.

The relational schema is defined as follows:

a. CORPUSTEXT (TextID, idType, Source, TextName, DateAquired, Language, LangVariant, TextPath)

b. ENVIRONMENT (EnvironID, Description, Remark)

c. READER (ReaderID, SurName, FirstName, OtherNames, Sex, DOB, Address, email, Speciality, OtherTraining)

d. RECORD (RecordID, ReaderID, TextID, TextData, Time, Duration, EnvironmentID, Format, NumChannels, SampleRate, BitRate, BitsPerSample)

e. TEXTTYPE (TextTypeID, TextType, Description)

f. UNIT (UnitID, RecID, UnitTypeID, F0, F1, F2, Duration, Intensity, Gaussian, MFCC)

g. UNITTYPE (UnitTypeID, Description, Category, Remark)

h. CODEBOOK (CodeID, Code, UnitID)

i. WORD (WordID, Word, POS, Meaning)

These are represented as mapped, in the conceptual schema design in Figure 4.The entity types in the read text corpus database include CorpusText, Word, TextType, Unit, UnitType, Reader, Record, CodeBook and Environment. They are all regular entities. The mapping of EER schema to Relational schema firstly involved using the regular (strong) entities type $E$ in the EER schema to derive a relation $R$ that comprises all the simple attributes of $\mathrm{E}$; and then choosing suitable key attributes of $\mathrm{E}$ as primary key for relation $\mathrm{R}$. Where multiple keys in E were identified in the ER design, the keys are retained so to serve as secondary (unique) keys of relation R. The primary keys are mainly necessary for maintaining entity uniqueness and indexing functions. 


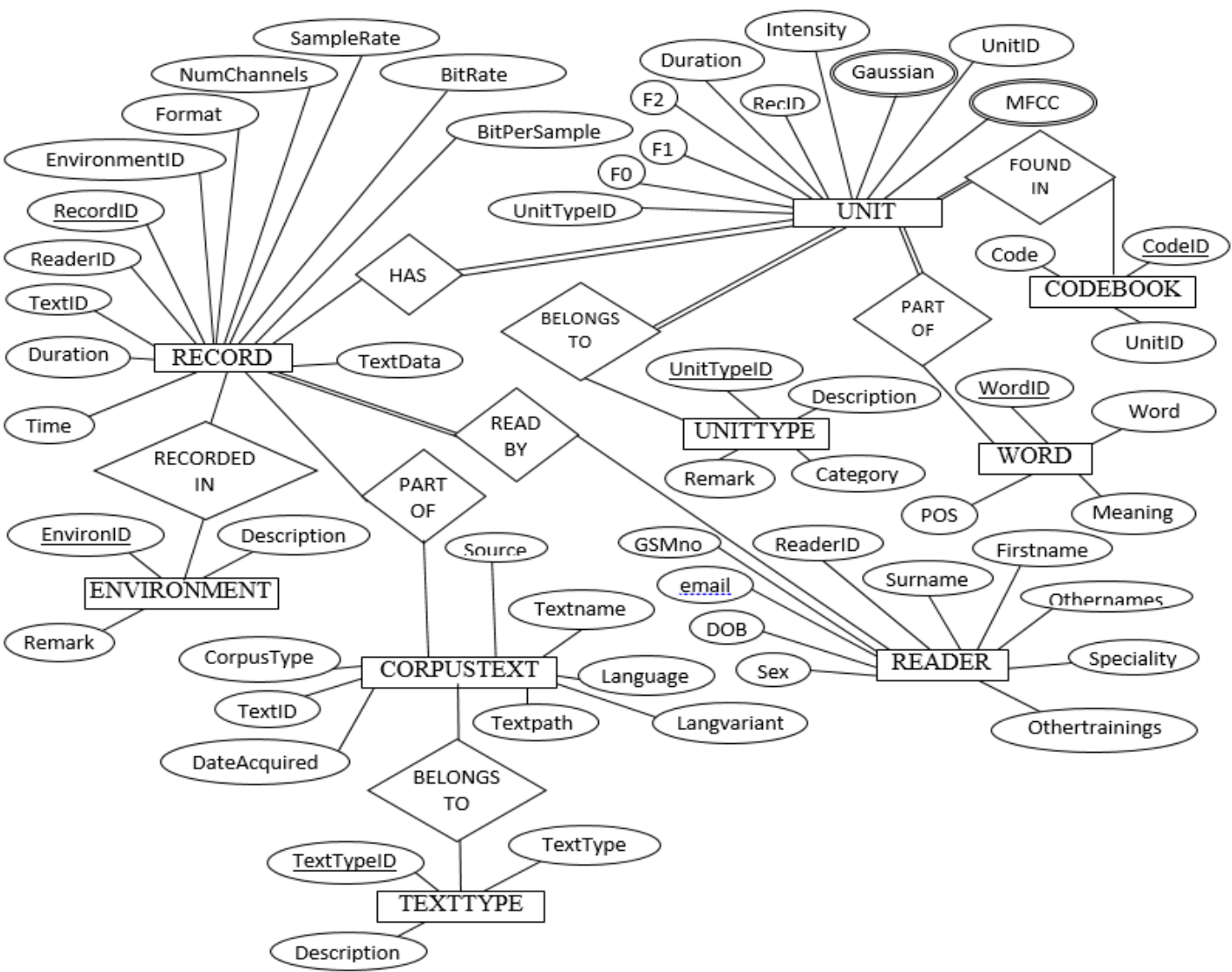

Figure 3: Extended Entity-Relationship model of the SY speech corpus database and its corresponding Relational Database Structure respectively

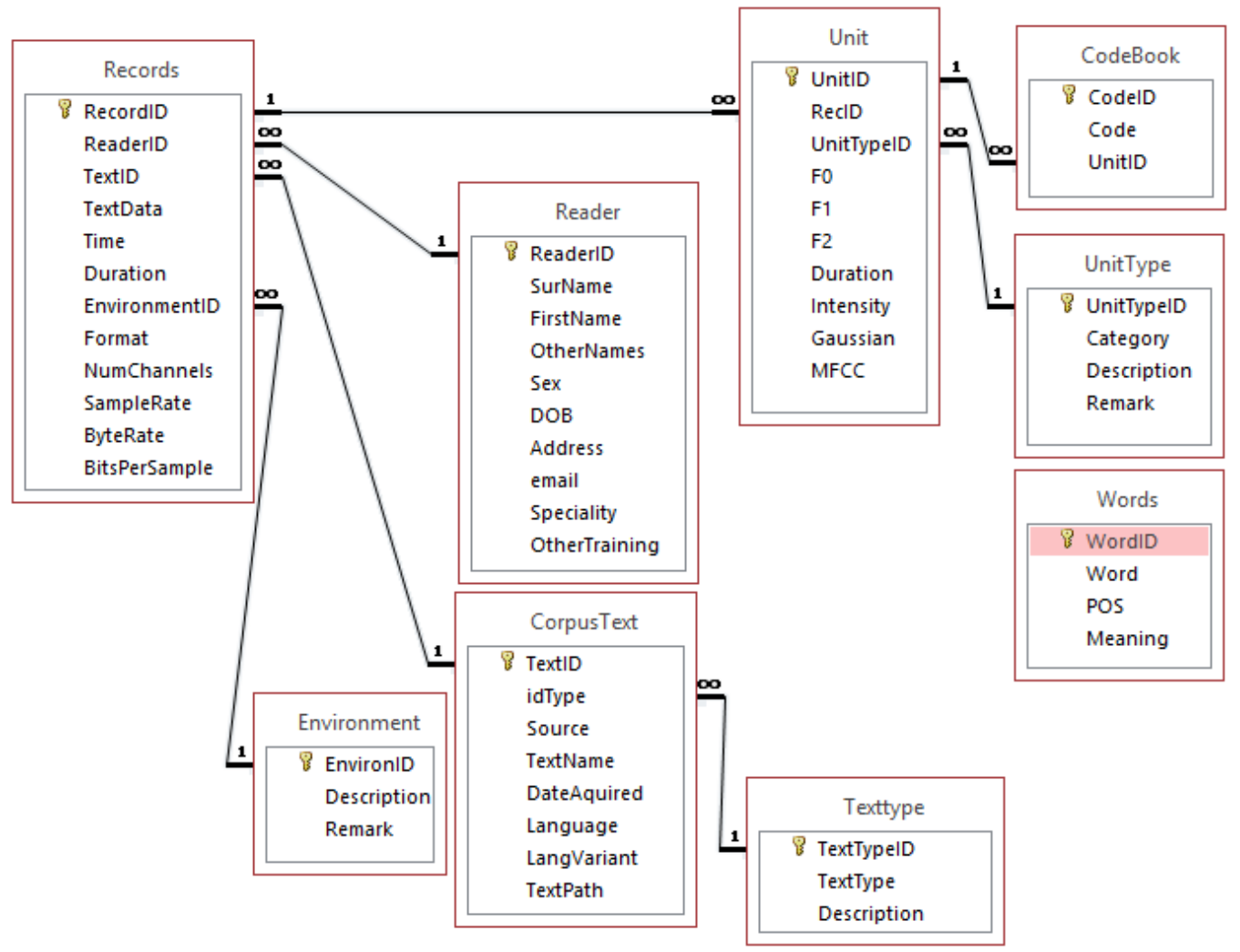

Figure 4: Relational Database Structure of the SY speech corpus database 


\subsection{Selection of Sentences for the Corpus}

A careful selection of sentences for the corpus is necessary. Steps were taken in the method, to make sure that there is a balance in the length and spread of syllabic events in the selected sentences for the corpus. The complexity of syllabic events in the sentences is restricted by relational algebraic expression in (1)

\section{$\sigma(([$ NoOfSyllable $]<=15$ AND}

$$
\text { [NoOfSyllable] }>=3)(\text { SENTENCES) }
$$

Thus, in the output

$$
\left.\exists\left\{\mathrm{s}_{0}, \mathrm{~S}_{1}, \mathrm{~S}_{2} \ldots \mathrm{s}_{(\mathrm{n}-1}\right)\right\} \in \mathrm{S} \text { s.t. }\left\{15<=\tilde{n}_{i}>=3\right\} \wedge\{\mathrm{n}\} \sim\{i\} \quad 2
$$

where $\mathrm{n}=$ Number of required sentences, $S \mathrm{~S}=$ Set of all sentences, $\aleph_{\mathrm{X}}=$ sentence of index $\mathrm{x}$, and $\tilde{n}_{i}=$ Number of events in sentence $i$. S is used to get phonetically balanced sentences from the corpus as follows:

$$
\begin{gathered}
S=-\sum_{i=1}^{I}\left|\frac{m_{i}}{m}-\frac{n_{i}+n^{\prime}}{n}\right| \\
m=\sum_{i=1}^{I} m_{i} \\
n=\sum_{i=1}^{I}\left(n_{i}+n^{\prime}{ }_{i}\right)
\end{gathered}
$$

when $I=$ Number of desired phonetic events,

$m_{i}=$ Number of $i^{\text {th }}$ corpus events,

$n_{i}=$ Number of $i^{\text {th }}$ events in the cumulative selection

$n_{i}^{\prime}=$ Number of the $i^{\text {th }}$ phonetic events in the scanned sentence. Scanning of sentences is repeated.

At each epoch, the sentence with the highest $\mathrm{S}$ is chosen for $n$ epochs. Thereafter, the selected sentences are shingled and sorted:

For Sentence $=\mathrm{abcab}$ and ShingleWidth $=2$

Where $a, b, c$ are syllables

Shingles (abcab,2)-> \{ConCat $(\mathrm{a}, \mathrm{b}), \operatorname{ConCat}(\mathrm{b}, \mathrm{c})$,

$$
\text { ConCat }(c, a)\}
$$

At each epoch, the sentence with the highest $\mathrm{S}$ is chosen for $\mathrm{n}$ epochs. Thereafter, the selected sentences are shingled and sorted:

\subsection{SY - Syllabification and Shingles () Function}

Syllabification (syllabication) is the separation of a word into syllables, whether spoken or written. Thus, in the context of this research, a syllabificator (syllabicator) is the software that can be used to perform syllabification (syllabication). It is a language-based operation.

The syllabificator model proposed for this research seeks to improve over the performance of the syllabicator in [16] and syllabificator in [13]. This model adopts the NLP concepts of alphabetic shingle and valid syllable mappings or structures to derive the valid syllabic tokens from the set of shingles generated from a given word.

NLP models that allot probabilities to strings of words are known as language models (LMs).The $\mathrm{N}$-gram is the simplest model that allots probabilities (likelihoods) to sentences, phrases and series of words. In NLP, the elements of an ngram can be phonemes, syllables, letters, words or pairs of these base kinds. The n-grams typically are collected from a text or speech corpus. N-gram model is a probabilistic model used for forecasting the next element in such a sequence in the form of a $(n-1)$-order Markov model. For simplicity and scalability, n-gram models are currently broadly used in communication theory, probability, biological sequence analysis, data compression and statistical NLP. N-grams are also called Shingles [22]. Shingling is used to convert a document or textual material to unique sets. At the word level it takes consecutive words and group them as a set. A k-gram is a consecutive set of $\mathrm{k}$ characters. By so doing, the set of all 1 -shingles at the word level is the bag of words model.

Now, let NGramAl represent the alphabetic shingling or character shingling function, that is, an n-gram in which the elements are letters within a word. The process is described as follows:

\section{String Array[n]NGramAl;}

String NGramAl ;

$$
\begin{aligned}
& \text { NGramAl (theWord, } l) \equiv\{S 0, S 1, \ldots, S n-1\} ; \\
& \text { theNGramAl }=[S 0, S 1, \ldots, S n-1] ;
\end{aligned}
$$

Where theWord is the target word;

$l$ is the NGramAlWidth (the number of character tokens in each n-gram in the set of all continuous $n$ sequences of character-tokens).

Where: $L E N(S i) \leq l$ and $0 \leq i \leq n-1$

An $n$-gram for a document is a sequence of $n$ characters that appears in the document.

Thus, NGram(“abcab”,2) returns \{“ab”, "bc”, “ca”\}

Likewise, NGramAl ("abcabcd", 3) returns \{“abc", "bca”, "cab", "bcd"\}.

Optionally, shingle is a bag, hence will return \{“abc", "bca", "cab", "abc", "bcd") containing two strings of "abc".

\subsubsection{The Sy-Syllabificator Design}

The design of the SY-Syllabificator consists of three logical modules or subsystem. These are:

$$
\begin{aligned}
& \text { a. SY-Syllabificator File/Sentence Reader module; } \\
& \text { b. SY-Syllabificator main module; and } \\
& \text { c. SY Syllable Structure Generation module. }
\end{aligned}
$$

The contiguous architecture and functional design of the system is presented in figure 5 .

The architecture and functional description of the three parts are presented in the next subsections.

\subsubsection{SY-Syllabificator File/Sentence Reader Module}

Figure 5 gives a graphical illustration of the process flow of the SY-syllabificator file/sentence reader module. This subsystem responsible for initializing the syllabification process at the beginning and also responsible for terminating the process at when there are no more sentences to read. It starts by reading in the File1 ("*.yor") Unicode file that contains the sentences been syllabified. Here, the file is 
delineated into sentences as necessary.

Furthermore, each sentence is read and then processed in a loop of the form:

\section{While (File 1.CurrentSentence. Trim() > “")}

\}else \{

System.File2. Write (Syllables \& Structure); Stop;

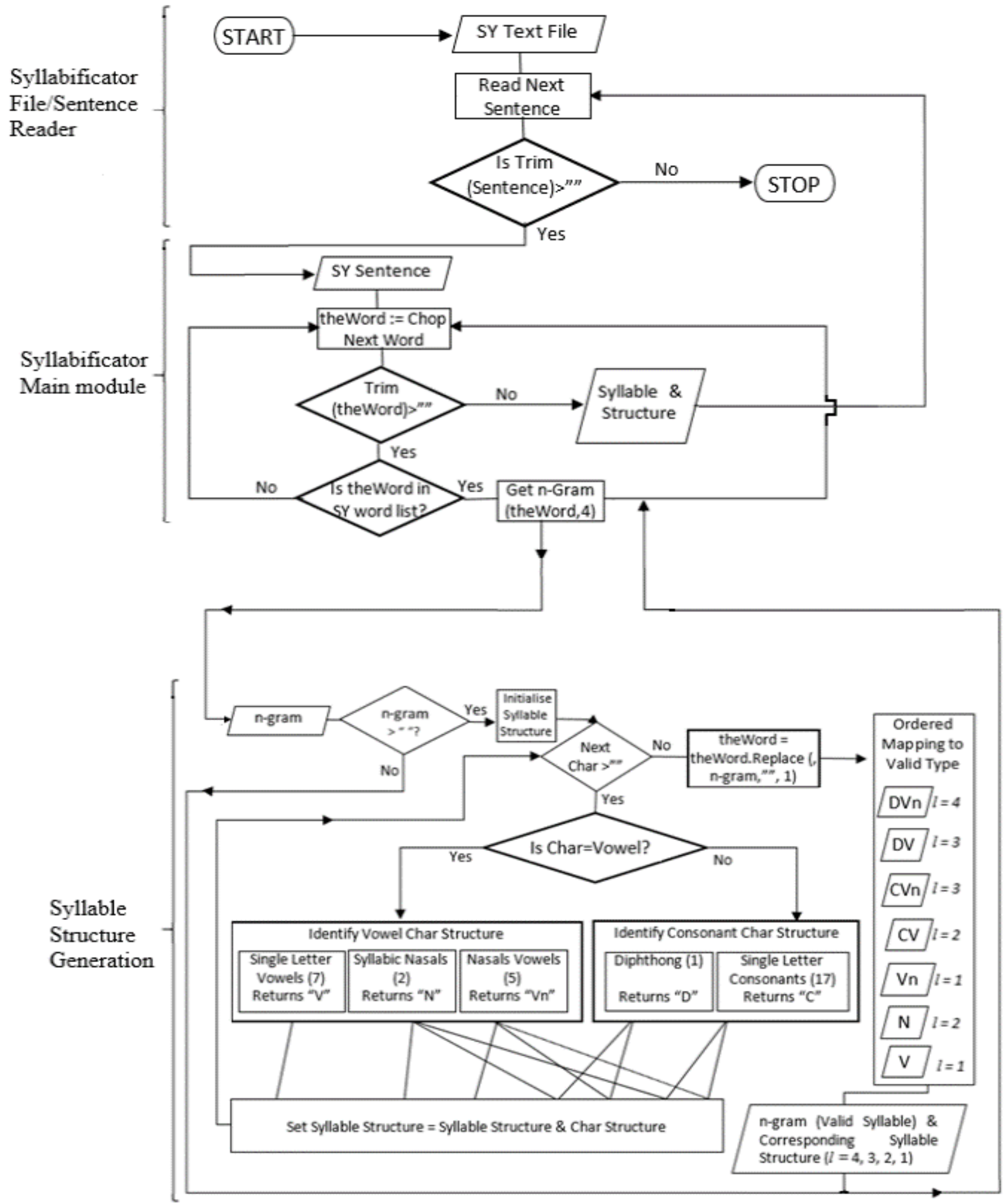

Figure 5: The architecture and functional design of the SY-Syllabificator 
The loop exits when the function File1.CurrentSentence.Trim() returns an empty string signaling no more sentences.

While the epochs continue, each read sentence is sent to the SY-syllabificator main module for necessary parsing into words and then to the SY syllable structure generation module where further processing over each epoch ultimately returns a duo of SY syllables and their corresponding syllable structures for each given sentence. The pair is written into another file File2 ("*..syl") in Unicode format.

The diacritic transformation is performed and tokenized into words. The word is then parsed to determine whether the structure is Yoruba before finally passed to the syllabication module. For each of the given word-lengths, a set of rules were designed to cover the possible combinations of characters and the syllables that could be formed from them.

The diacritic transformation is performed and tokenized into words. The word is then parsed to determine whether the structure is Yoruba before finally passed to the syllabication module. For each of the given word-lengths, a set of rules were designed to cover the possible combinations of characters and the syllables that could be formed from them.

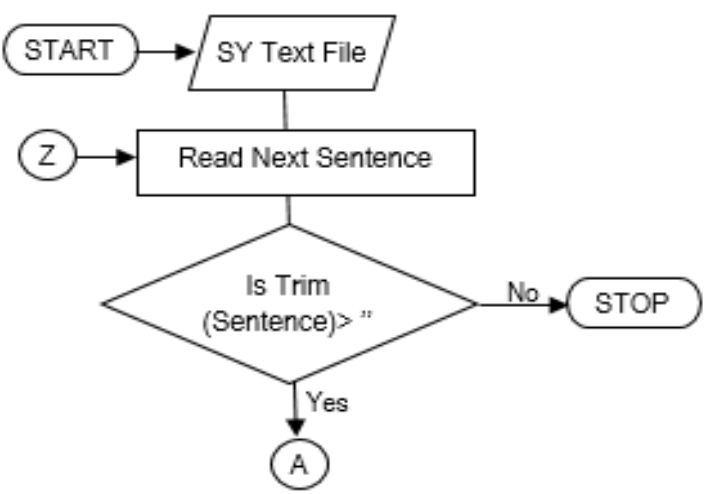

Figure 6: SY-Syllabificator File/Sentence Reader

\subsubsection{SY-Syllabificator Main Module}

Figure 7 gives a functional graphical representation of the SYsyllabificator main module. This subsystem, on each epoch created in by the SY-syllabificator file/sentence reader module, receives a SY sentence as its input.

Furthermore, it parses the sentence into word tokens. It then creates a loop for each word in which it generates the NGramAl(theWord,4) per word, thereby generating quasisyllable tokens of widths 1 to 4 . Moreover, the subsystem passes each set of NGramAl tokens generated to SY syllabificator syllable structure generation module where syllable structures are generated.

\subsubsection{SY-Syllabificator Syllable Structure \\ Generation Module}

This is the module that is actually responsible for generating syllable structures and returning valid syllables for a given word and for a sentence over the various loops. The process is illustrated by Figure 8 . The corresponding NGramAl tokens for each word generated from the SY-syllabificator main module are processed in this module. The process involves the generation of syllable structures for each quasi-syllable from the previous. Then the generated structures are mapped to a list of seven ordered structure prototypes. These seven represent the valid prototypes allow in SY writing.

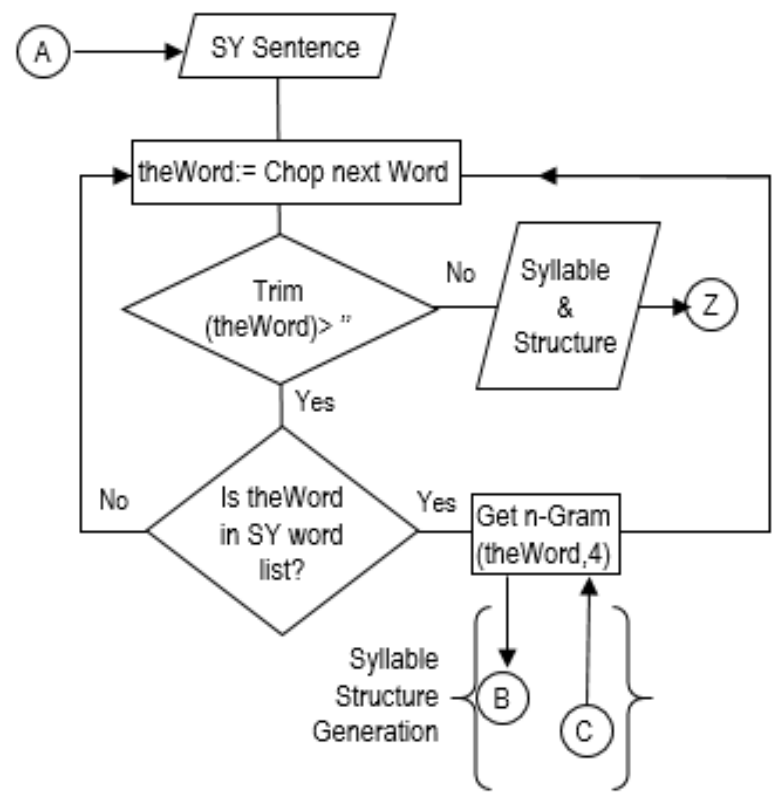

Figure 7: SY-Syllabificator Main Module.

Essentially, at this juncture, the mapping operation returns only valid syllables and their corresponding valid syllable structures while invalid ones are dropped. These are later returned as a duo of SY syllables $(\sigma)$ and their corresponding syllable structures $\left(\sigma^{\prime}\right)$ for each given sentence. These processeswere repeated for all words of all sentences in File1 ("*.yor") file. One obvious advantage of this design is that in deciding the validity of each syllable, iteration is done only by mapping to seven syllable structures. These are of V, N, CV, CVn, Vn, DV and CVn patterns.

$$
\sigma^{\prime} \in\{\mathrm{V}, \mathrm{N}, \mathrm{CV}, \mathrm{CVnVn}, \mathrm{DV} \text { and } \mathrm{CVn}\}
$$

This is bound to be faster than the method of [16]and [19] which runs on each given word-length, a set of rules that were designed to cover the possible combinations of characters and the syllables that could be formed from them. Moreover, adaptation of this design to other languages will involve just one step of defining valid syllable structures for the target language. There will be no need to redefine syllabification rules for the new language.

With the model in Figure 8 , it is possible to generate equivalent syllabic maps for the syllabic NGrams for each word provided the input is replaced with each Syllabic NGram. Thus, the Yoruba Syllable Mapping Generator modifies to the structure in Figure 8

$$
\begin{aligned}
& \text { Where } \sigma=\text { Set } \ni \sigma \mid \rightarrow \sigma^{\prime} \epsilon \sigma^{\prime} \\
& \sigma=\text { the Set of SY Syllables } \\
& \sigma=\text { a given syllable, an element of } \sigma \\
& \sigma^{\prime}=\text { a given syllable structure, an element of } \sigma^{\prime}
\end{aligned}
$$




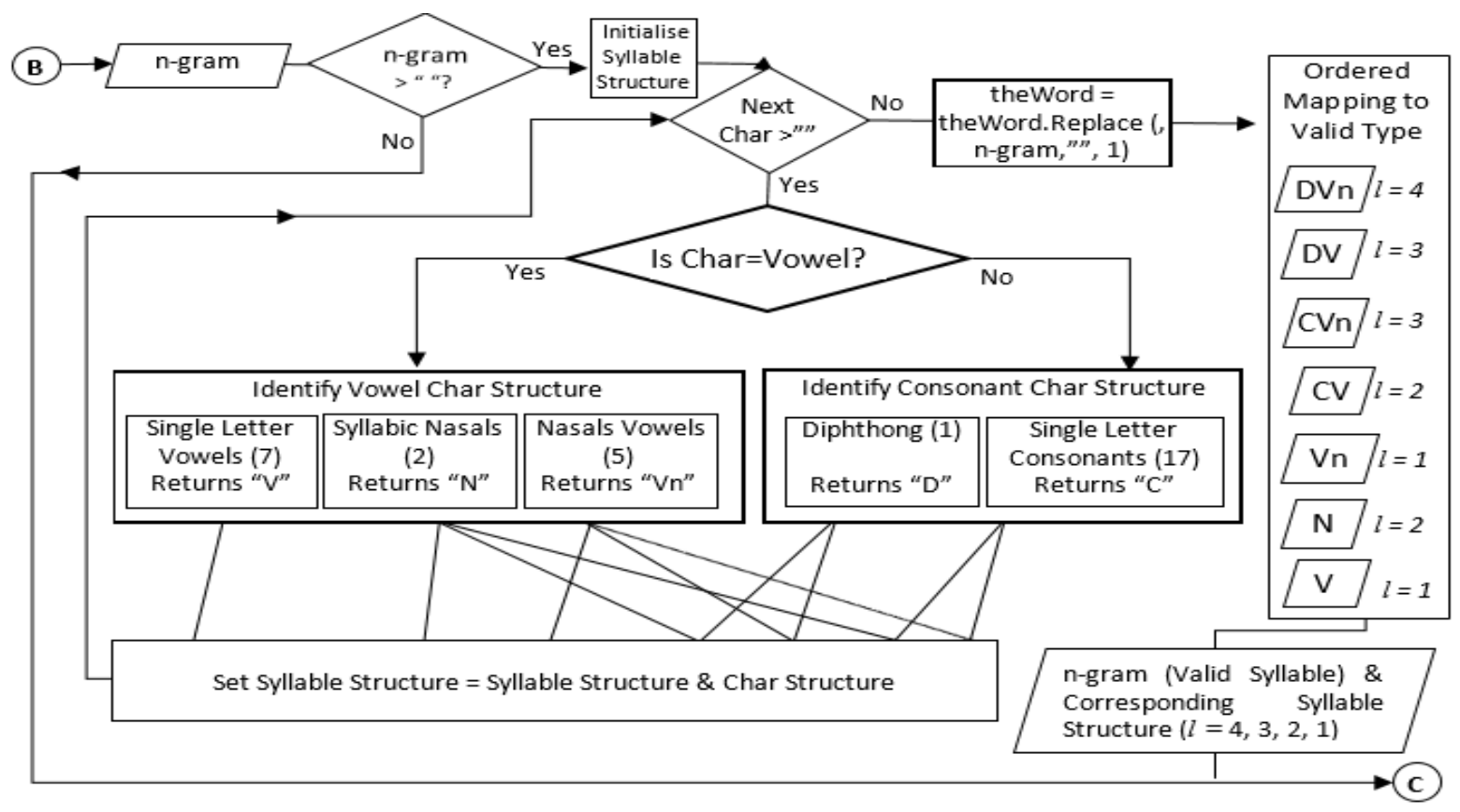

Figure 8: SY-Syllabificator Syllable Structure Generation Module

\section{RESULT}

A combination of both manual and scripting methods was used in annotating the recorded speech files for the SY TTS.

Segmentation of recorded utterances into words and then syllables was accomplished using Praat toiterating over the recorded speech files and the corresponding texts. Thereafter Praat text grid editor was used to manually correct corporal segmentation errors by listening to each units and visually tweaking unit boundaries on the respective tiers of the text grid. This is a strenuous exercise but necessary to improve the accuracy of the corpus.

\subsection{Feature Extraction of the Corpus}

Extraction of pitch features for the SY syllables was performed using Praat scripts.

Table 2 depicts the extracted pitch components up to the P10 for certain syllables. Only P0, P1 and P2 were stored on the database in view of the design in Figure 3.

Table 3. Extracted Intensity Features of Certain Syllables in Decibels

Table 4. Extracted Duration Features of Certain Syllables in Seconds

Table 5. Mean Values for Extracted Features of Syllables

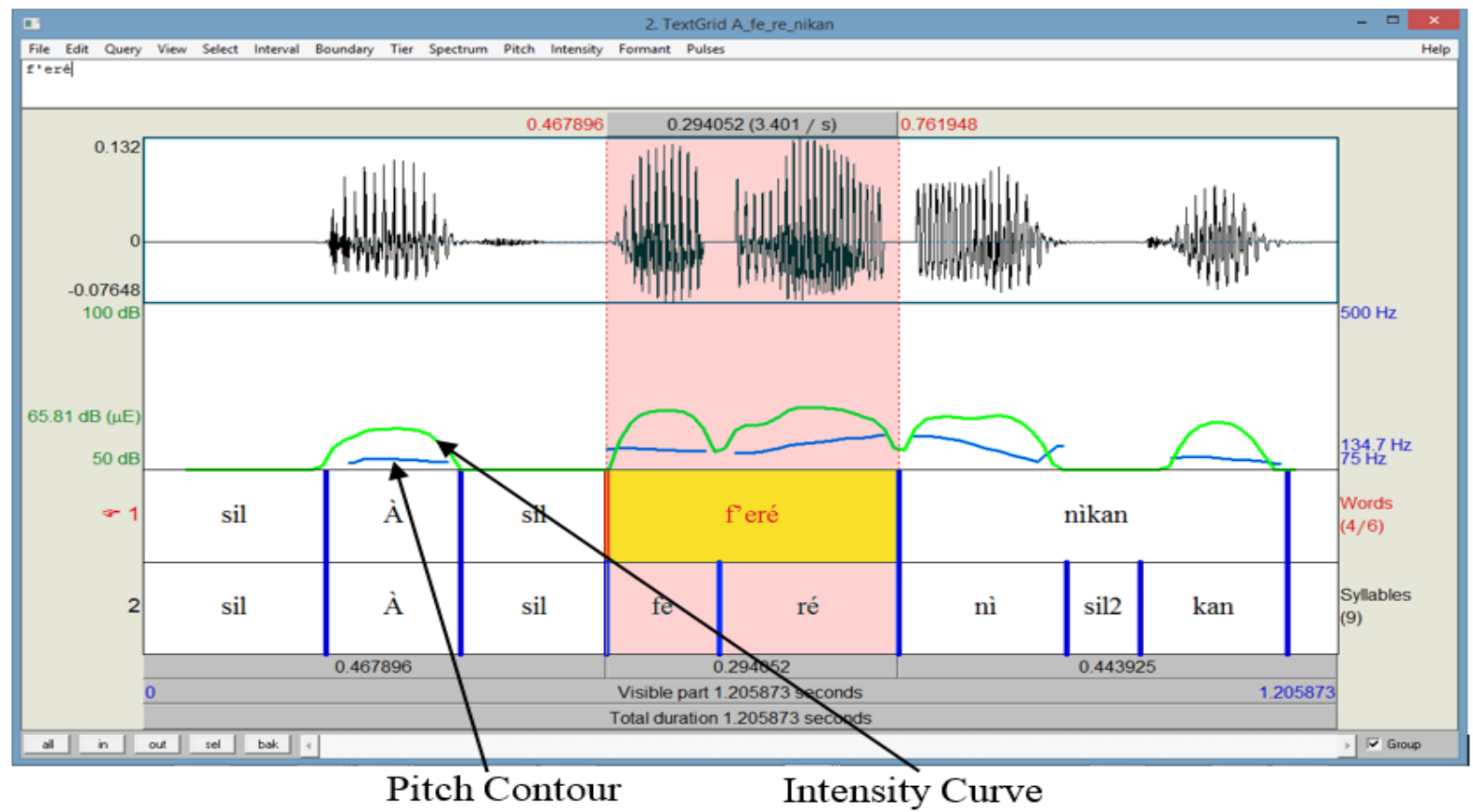

Figure 9: Praat Textgrid Utterance Annotation fora 2-Tier (Words Tier and Syllables Tier)Annotation of "à f" eré nikan" 
File type $=$ "ooTextFile"

Object class = "TextGrid"

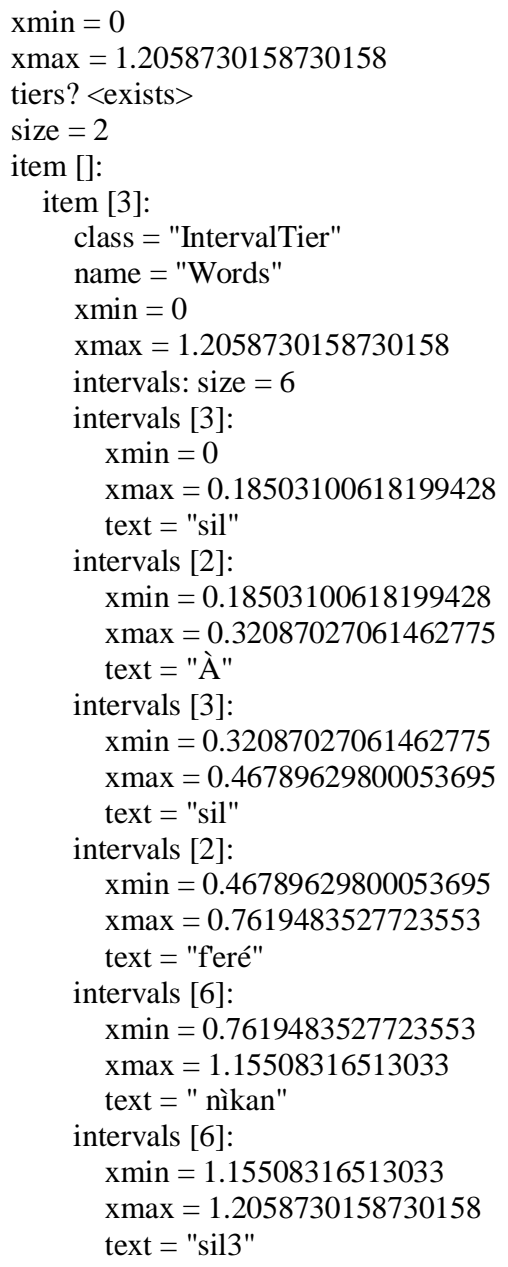

Figure 10: Textgrid Data for "à f' eré nikan" Utterance Showing Words Tier Annotation (Higher Level).
File type $=$ "ooTextFile"

Object class $=$ "TextGrid"

$\mathrm{xmin}=0$

$\operatorname{xmax}=1.2058730158730158$

tiers? <exists>

size $=2$

item []:

item [2]:

class = "IntervalTier"

name $=$ "Syllables"

$\mathrm{xmin}=0$

$\mathrm{xmax}=1.2058730158730158$

intervals: size $=9$

intervals [3]:

$\mathrm{xmin}=0$

$x \max =0.18503100618199428$

text $=$ "sil"

intervals [2]:

$\mathrm{xmin}=0.18503100618199428$

$x \max =0.32087027061462775$

text $=$ "À"

intervals [3]:

$\mathrm{xmin}=0.32087027061462775$

$\mathrm{xmax}=0.46789629800053695$

text $=$ "sil"

intervals [2]:

$\mathrm{xmin}=0.46789629800053695$

$\mathrm{xmax}=0.581362036526619$

text $=$ "fe"

intervals [6]:

$\mathrm{x} \min =0.581362036526619$

$x \max =0.7619483527723553$

text $=$ "ré"

intervals [6]:

$\mathrm{xmin}=0.7619483527723553$

$x \max =0.9313479060648159$

text $=$ " nì"

intervals [4]:

$\mathrm{xmin}=0.9313479060648159$

$\mathrm{xmax}=1.0064590287510955$

text $=$ "sil2"

intervals [23]:

$\mathrm{xmin}=1.0064590287510955$

$\mathrm{x} \max =1.15508316513033$

text $=$ "kan"

intervals [5]:

$\mathrm{xmin}=1.15508316513033$

$\mathrm{xmax}=1.2058730158730158$

text $=$ "sil3"

Figure 11: Textgrid Data for "À f'eré nikan" Utterance Showing Syllables Tier Annotation (Lower Level)

Table 2. WordsExtracted Pitch Features of Certain Syllables in Hertz

\begin{tabular}{|c|c|c|c|c|c|c|c|c|c|c|c|c|}
\hline Id & $\mathbf{S}$ & P0(Hz) & P1(Hz) & P2(Hz) & P3(Hz) & P4(Hz) & P5(Hz) & P6(Hz) & P7(Hz) & P8(Hz) & P9(Hz) & P10(Hz) \\
\hline 36 & Yún & 110.2868 & 114.1006 & 116.7839 & 119.5503 & 122.3146 & 125.3720 & 128.8481 & 132.1298 & 134.8732 & 137.7730 & 140.5459 \\
\hline 47 & Yún & 232.4902 & 226.5086 & 218.1436 & 209.0240 & 200.0097 & 191.3129 & 183.1027 & 174.5445 & 165.5585 & 157.6415 & 150.4485 \\
\hline 72 & yun & 102.5374 & 103.8606 & 105.6650 & 107.5538 & 108.9202 & 110.5460 & 112.2565 & 113.9411 & 115.6384 & 117.3619 & 118.3995 \\
\hline 108 & Yù & 5.6793 & 96.6440 & 96.5269 & 96.9954 & 98.0269 & 3835 & 8485 & & & 101.8138 & 101.8186 \\
\hline
\end{tabular}




\begin{tabular}{|c|c|c|c|c|c|c|c|c|c|c|c|c|}
\hline 119 & Yù & 143.2035 & 134.2543 & 126.4178 & 119.2112 & 113.1261 & 106.4613 & 98.8049 & 92.2552 & 86.7868 & 81.6931 & 76.1109 \\
\hline 155 & Yú & 219.3048 & 212.0127 & 202.4239 & 193.3997 & 185.7468 & 178.0436 & 171.7262 & 165.9273 & 161.4758 & 157.8539 & 154.3605 \\
\hline 828 & yё & 95.8243 & 96.7083 & 97.9845 & 99.5912 & 101.5147 & 104.4873 & 108.2068 & 112.4411 & 117.3821 & 122.9313 & 128.9399 \\
\hline 972 & ye & 92.6868 & 92.5907 & 92.8153 & 93.7419 & 94.5734 & 93.8305 & 93.4863 & 94.0978 & 95.5076 & 96.7879 & 98.2397 \\
\hline 1008 & yçn & 93.0858 & 94.0544 & 95.5027 & 96.7725 & 97.5742 & 98.5053 & 100.0424 & 101.4363 & 103.3852 & 105.7821 & 107.8814 \\
\hline 1019 & yçn & 215.2838 & 210.6033 & 202.8377 & 192.1555 & 181.8663 & 172.8903 & 164.0620 & 155.5401 & 147.4894 & 140.7716 & 133.9680 \\
\hline 2016 & wí & 118.6305 & 123.8112 & 130.9109 & 137.1851 & 142.8654 & 148.6868 & 156.3495 & 160.0578 & 163.6268 & 166.1155 & 168.4327 \\
\hline 2027 & wí & 188.5958 & 186.9798 & 184.4597 & 180.2741 & 175.8855 & 171.1899 & 166.7354 & 160.1373 & 154.0799 & 145.0943 & 138.2646 \\
\hline 2171 & wë & 181.5146 & 176.2070 & 170.1165 & 165.0042 & 161.0991 & 158.5885 & 156.2436 & 152.4230 & 147.8677 & 142.7734 & 136.8484 \\
\hline 2232 & wè & 87.5485 & 89.8510 & 92.3013 & 95.0728 & 98.4751 & 100.7805 & 102.7393 & 104.7054 & 106.3491 & 106.3615 & 105.7807 \\
\hline 2279 & wé & 177.5540 & 172.4199 & 166.3148 & 161.8967 & 157.1944 & 153.2258 & 150.4489 & 147.1709 & 143.2561 & 139.2135 & 134.4185 \\
\hline 2315 & we & 172.5931 & 166.4979 & 160.7098 & 155.1876 & 149.6868 & 143.1152 & 135.3168 & 127.4450 & 119.9253 & 112.5183 & 105.5440 \\
\hline 2376 & wç & 101.8549 & 104.1377 & 106.6572 & 108.4570 & 110.1324 & 110.9517 & 111.4319 & 112.5763 & 113.7578 & 114.7338 & 115.2594 \\
\hline 2772 & ù & 95.2252 & 95.9270 & 96.4599 & 97.4349 & 98.1635 & 98.3023 & 98.5159 & 98.2636 & 97.5455 & 96.7111 & 95.9025 \\
\hline 2808 & ú & 140.6187 & 145.8414 & 151.8351 & 156.7228 & 160.5586 & 164.3926 & 168.5562 & 172.5605 & 175.8520 & 178.4230 & 180.7496 \\
\hline 2819 & ú & 234.4417 & 231.1811 & 224.2543 & 214.7099 & 205.3312 & 196.3984 & 187.6061 & 179.3871 & 171.0912 & 162.5179 & 153.1596 \\
\hline 3024 & tu & 114.3018 & 117.8508 & 118.6078 & 118.5431 & 118.9915 & 119.1673 & 119.4314 & 119.9830 & 120.9926 & 121.3890 & 121.1462 \\
\hline 3215 & tö & 199.1879 & 189.8251 & 177.0654 & 166.9405 & 158.7295 & 151.2303 & 144.0488 & 137.0716 & 130.3283 & 124.4378 & 118.1805 \\
\hline 3240 & tô & 109.7954 & 108.9180 & 108.7385 & 109.4576 & 110.4345 & 111.2468 & 111.9139 & 112.6645 & 112.5695 & 111.5007 & 110.0918 \\
\hline 3312 & tó & 146.2979 & 147.2157 & 148.9607 & 151.3603 & 154.4362 & 158.2915 & 162.1161 & 165.0174 & 167.7229 & 171.7020 & 182.7588 \\
\hline 3575 & $\mathrm{ti}$ & 185.0830 & 178.9860 & 168.4533 & 160.4771 & 152.4052 & 143.7944 & 134.9659 & 126.4339 & 118.7894 & 111.5541 & 104.3106 \\
\hline 3827 & te & 187.1610 & 176.7660 & 162.6942 & 152.4320 & 140.7850 & 133.6531 & 125.6845 & 118.1189 & 111.5541 & 105.2271 & 99.7080 \\
\hline 4043 & tà & 142.6785 & 129.1879 & 119.7930 & 109.3154 & 100.4436 & 89.4442 & 80.0444 & 78.0786 & & & \\
\hline 4068 & tá & 136.5525 & 136.9234 & 137.4230 & 138.5579 & 140.8469 & 143.8584 & 147.1359 & 151.2560 & 154.9611 & 157.5654 & 161.1818 \\
\hline 4079 & tá & 204.5551 & 194.8978 & 182.5991 & 171.0992 & 161.6676 & 154.2606 & 147.7255 & 141.4879 & 135.8092 & 129.3375 & 123.0552 \\
\hline 4187 & sún & 231.5180 & 223.1693 & 211.7717 & 201.0198 & 191.7057 & 183.4371 & 175.6478 & 168.4265 & 161.7610 & 154.9418 & 149.1385 \\
\hline 4212 & sun & 129.8070 & 128.0456 & 126.9342 & 126.7099 & 126.8509 & 127.5854 & 128.7999 & 130.8564 & 133.5138 & 136.5052 & 139.4013 \\
\hline 4223 & sun & 209.8370 & 196.2031 & 180.9702 & 167.8933 & 156.2549 & 146.6017 & 138.2234 & 131.7938 & 125.7905 & 119.7435 & 113.9173 \\
\hline 4835 & sí & 214.7763 & 212.3132 & 206.3359 & 198.3963 & 190.2926 & 182.2608 & 173.9031 & 165.1563 & 156.4373 & 150.5354 & 147.9966 \\
\hline 5256 & sán & 132.8687 & 134.6006 & 136.9148 & 139.8811 & 143.1361 & 146.5432 & 149.4802 & 152.5981 & 155.8062 & 158.7495 & 163.3063 \\
\hline 5267 & sán & 185.3142 & 177.5012 & 168.1271 & 160.3069 & 153.2171 & 147.0936 & 140.5348 & 134.1807 & 127.7895 & 121.3457 & 116.5960 \\
\hline 5292 & san & 104.5808 & 103.7416 & 103.2944 & 103.1315 & 103.2711 & 103.9493 & 105.1077 & 106.1620 & 106.6439 & 105.9845 & 105.4681 \\
\hline 5483 & rún & 193.4823 & 187.8375 & 179.8767 & 173.9368 & 167.6460 & 161.2152 & 154.5212 & 148.7684 & 143.2890 & 137.7543 & 132.1779 \\
\hline 5591 & rú & 174.0365 & 169.9150 & 164.2592 & 158.8045 & 154.6704 & 150.9763 & 147.2686 & 143.3871 & 138.6858 & 133.9659 & 128.4217 \\
\hline 5796 & rö & 103.5946 & 104.3598 & 105.0165 & 106.3065 & 110.0354 & 114.7238 & 119.1592 & 122.7599 & 125.7177 & 127.5593 & 130.3069 \\
\hline 5807 & rö & 210.3324 & 200.7521 & 188.5765 & 179.0679 & 172.7375 & 168.3976 & 162.8347 & 156.4707 & 149.2341 & 141.2491 & 135.6740 \\
\hline 5868 & rò & 95.6464 & 95.4354 & 95.1566 & 94.9286 & 94.6315 & 94.0123 & 93.5932 & 92.5909 & 91.2964 & 89.4979 & 87.4246 \\
\hline 5904 & ró & 114.6160 & 118.7701 & 123.2932 & 127.7274 & 132.0720 & 135.7715 & 139.6171 & 143.2283 & 146.9604 & 150.5714 & 153.8145 \\
\hline 6084 & rì & 89.8278 & 91.9655 & 92.9981 & 93.7721 & 95.1567 & 96.5677 & 98.0265 & 99.5412 & 100.3989 & 100.1362 & 99.9257 \\
\hline 6131 & rí & 197.3165 & 191.9624 & 185.2218 & 178.2485 & 173.1483 & 168.1049 & 163.3125 & 158.6087 & 153.5073 & 149.9926 & 147.7551 \\
\hline 6336 & rê & 94.7908 & 95.0096 & 96.0253 & 98.0619 & 99.3768 & 100.7763 & 100.7477 & 100.6010 & 99.7854 & 98.0745 & 95.2895 \\
\hline 6347 & rê & 151.0071 & 143.3940 & 135.3423 & 129.5613 & 122.8102 & 115.8337 & 108.8712 & 101.1426 & 95.3914 & 87.5491 & 77.2093 \\
\hline 6383 & rè & 174.1443 & 167.9768 & 161.0590 & 154.4093 & 147.0929 & 140.3120 & 132.8154 & 125.2644 & 116.8095 & 108.9242 & 100.5812 \\
\hline 6444 & re & 102.5300 & 104.2159 & 106.7237 & 109.9657 & 113.1108 & 115.5739 & 117.1953 & 118.5326 & 120.2658 & 121.7172 & 121.9862 \\
\hline 6588 & rán & 103.6592 & 106.7463 & 110.5681 & 113.7003 & 117.0128 & 120.7428 & 124.1899 & 127.5918 & 130.5301 & 133.2128 & 136.3235 \\
\hline 6948 & $\mathrm{pu}$ & 119.6669 & 120.1871 & 120.2812 & 121.5033 & 122.4372 & 122.4504 & 122.6654 & 123.0807 & 123.6869 & 124.4807 & 125.2517 \\
\hline 6959 & $\mathrm{pu}$ & 174.5557 & 165.9387 & 154.5329 & 145.9635 & 136.5809 & 126.7691 & 119.3324 & 111.9434 & 105.1094 & 99.2102 & 93.0700 \\
\hline 7020 & pön & 136.5414 & 137.5673 & 139.2344 & 141.6772 & 144.9693 & 149.7539 & 153.9433 & 158.1365 & 162.4653 & 168.5872 & 175.9485 \\
\hline 7031 & pön & 195.4338 & 187.0324 & 177.4424 & 169.0887 & 162.0680 & 156.1590 & 149.6166 & 143.1699 & 138.2129 & 133.9485 & 128.8799 \\
\hline 7128 & pö & 130.2202 & 130.9704 & 133.7646 & 137.5568 & 140.5442 & 142.7349 & 144.6516 & 145.5691 & 148.1043 & 168.2457 & 183.9236 \\
\hline 7139 & pö & 193.2768 & 184.4333 & 176.1794 & 169.7370 & 162.3425 & 154.3446 & 146.8027 & 139.3522 & 133.9666 & 136.5816 & 138.3581 \\
\hline 7175 & pô & 171.1309 & 163.7154 & 154.4687 & 145.8284 & 137.4860 & 129.5704 & 122.1538 & 114.9013 & 107.6883 & 100.3744 & 96.0860 \\
\hline 7211 & pò & 142.3099 & 133.5723 & 123.6602 & 114.0543 & 103.7964 & 95.0780 & 85.1727 & & & & \\
\hline 7272 & po & 120.3865 & 120.5121 & 121.4541 & 122.6869 & 123.4825 & 124.0364 & 125.1013 & 126.0461 & 126.8434 & 127.4974 & \\
\hline 7344 & pín & 139.5456 & 141.5284 & 144.0085 & 147.6849 & 151.3667 & 156.4148 & 160.5640 & 163.7198 & 167.8586 & 175.3529 & 182.5421 \\
\hline 7427 & pì & 143.9262 & 136.7140 & 124.7867 & 114.3435 & 103.5815 & 93.2548 & 84.2498 & 78.1413 & & & \\
\hline 7452 & pí & 143.1520 & 147.6499 & 153.9392 & 156.9582 & 160.0166 & 167.6540 & 177.4438 & 186.4619 & 194.3550 & 200.9262 & 206.7099 \\
\hline
\end{tabular}




\begin{tabular}{|rcrrrrrrrrrrr|}
\hline 7740 & pe & 122.1183 & 122.8530 & 124.0040 & 124.6958 & 125.5146 & 127.2916 & 128.9886 & 129.7889 & 131.5770 & 132.0410 & 132.3486 \\
\hline 7992 & pá & 125.1481 & 126.1960 & 126.4430 & 128.1137 & 130.2569 & 134.7177 & 148.6715 & 155.8587 & 163.7572 & 170.5487 & 176.0600 \\
\hline 8172 & ó & 102.5543 & 102.6171 & 101.9878 & 100.9551 & 99.6758 & 98.1604 & 96.5272 & 95.1005 & & & \\
\hline 8208 & ö & 127.4035 & 129.7184 & 132.7403 & 135.9222 & 139.8575 & 143.2412 & 147.0108 & 150.3039 & 153.4383 & 158.1206 & 165.2854 \\
\hline 8316 & ó & 131.0290 & 133.8359 & 137.6494 & 141.1306 & 143.6090 & 146.0720 & 148.7440 & 151.4880 & 154.9050 & 159.0928 & 164.7331 \\
\hline 8568 & nu & 116.0371 & 120.4741 & 122.9006 & 125.3728 & 127.9535 & 131.1776 & 134.2913 & 135.2789 & 136.2629 & 138.7426 & 140.9736 \\
\hline 8759 & nö & 182.7529 & 179.5636 & 176.3399 & 173.9731 & 168.3708 & 161.3567 & 156.1158 & 150.6430 & 145.0609 & 140.0493 & 135.0702 \\
\hline 8820 & nò & 103.0723 & 103.9102 & 105.3424 & 108.3500 & 109.5654 & 109.8184 & 110.3222 & 110.2477 & 109.6510 & 108.1409 & 106.2129 \\
\hline 9072 & ní & 124.9842 & 129.3413 & 134.6490 & 141.6548 & 146.7214 & 150.5791 & 155.5651 & 161.8433 & 167.7445 & 173.3981 & 181.3544 \\
\hline 9227 & në & 217.1133 & 214.1167 & 206.6342 & 198.8371 & 192.2712 & 186.3646 & 178.4348 & 173.4134 & 166.1357 & 161.0506 & 154.8674 \\
\hline 9371 & ne & 201.4201 & 194.5945 & 186.2822 & 177.7789 & 170.2256 & 161.3443 & 148.9259 & 139.4763 & 130.0613 & 124.0081 & 117.8293 \\
\hline 9587 & nà & 190.1052 & 181.1539 & 171.0764 & 161.1857 & 152.9200 & 145.1191 & 135.4430 & 124.8803 & 114.4736 & 104.3692 & 94.0359 \\
\hline 9659 & na & 200.2234 & 200.2172 & 189.4895 & 179.9458 & 170.6450 & 160.0780 & 151.8110 & 142.6642 & 133.9364 & 125.5463 & 118.0113 \\
\hline 9720 & n & 123.7862 & 125.2350 & 126.8714 & 130.3454 & 132.7463 & 133.8631 & 134.9418 & 136.5609 & 137.7041 & 138.8782 & 140.3006 \\
\hline 10152 & mô & 107.1538 & 109.2042 & 109.0776 & 107.1925 & 106.7948 & 107.2227 & 107.5699 & 107.9243 & 107.9318 & 107.6878 & 107.7892 \\
\hline
\end{tabular}

Table 3. Extracted Intensity Features of Certain Syllables in Decibels

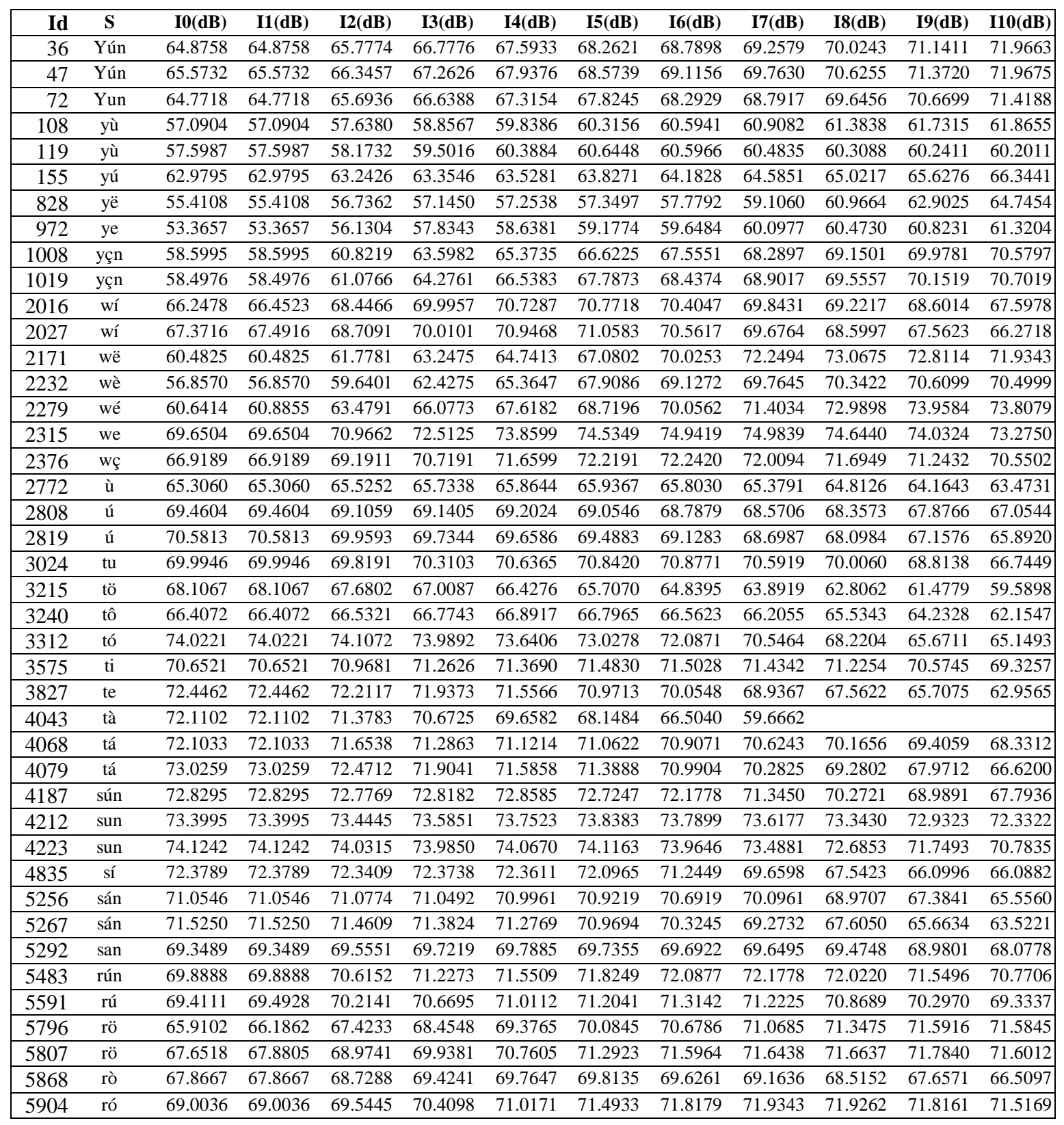




\begin{tabular}{|c|c|c|c|c|c|c|c|c|c|c|c|c|}
\hline 6084 & rì & 4920 & 20 & 6.3 & & 3.3878 & & & & 0.7794 & & \\
\hline 6131 & rí & & .5512 & 5365 & & .3540 & 1868 & & & & 8.3389 & 674754 \\
\hline 63 & rê & & & & & & & & & & & \\
\hline 6347 & rêt & 56 & .9556 & 7.0644 & .4265 & .0848 & .5277 & 69.69 & .1959 & 68.66 & 8.0600 & 6.3967 \\
\hline 6383 & rè & 1522 & .1522 & 8.2394 & 9.1107 & 9.7496 & 70.1082 & 70.2649 & 70.2544 & 70.0793 & 9.7266 & 69.1108 \\
\hline 6444 & re & 8679 & $\begin{array}{l}65.8679 \\
\end{array}$ & 66.6605 & 7.5559 & 8.1994 & 3.6823 & 68.9085 & 3.9288 & 8.8379 & 8.5985 & 88.2055 \\
\hline 6588 & rán & & 3.5597 & 5.2559 & .4126 & .0933 & 5294 & 67.8 & 528 & 7.9866 & 8.0050 & 67.9437 \\
\hline 6948 & $\mathrm{p}$ & & 30 & 57 & 78 & 5.9227 & 344 & & & 22 & 53.8971 & 61.9568 \\
\hline 6959 & $\mathrm{pu}$ & 1171 & 7.1171 & 67.4826 & 67.1708 & 67.2332 & 67.2601 & 66.6 & 65.8089 & 64.6889 & 62.9965 & 60.4148 \\
\hline 7020 & & 46 & 8.1546 & 68.1817 & 68.1111 & 67.8852 & 67.5441 & 66.9 & 5.2014 & 65.1048 & 63.7920 & 62.2038 \\
\hline 7031 & ön & 6717 & 68.6717 & 68.6592 & 68.5067 & 68.2133 & 67.7132 & 66.7741 & 5.4726 & 63.8557 & 61.8729 & 59.8717 \\
\hline 7128 & $\mathrm{p}$ & 5983 & 65.5983 & 66.6513 & 67.6030 & 68.1031 & 68.0593 & 67.5 & 66.0145 & 63.7548 & 62.1635 & 62.0135 \\
\hline 7139 & pö & 9809 & .9809 & 67.1750 & 3.02 & 3.4178 & .3632 & 33 & 6.1112 & 63.31 & 60.5972 & 59.8722 \\
\hline 7175 & pô & .9095 & 9.9095 & 70.0355 & 46 & 0.4997 & 70.7197 & 70.4 & & 68.9580 & 67.9578 & 66.2535 \\
\hline 7211 & pò & 19 & 72.1619 & 71.9208 & 71.0511 & 70.0060 & 68.9749 & 67.8043 & & & & \\
\hline 7272 & po & 8964 & 69.8964 & 69.9725 & 69.9748 & 69.7970 & 69.4157 & 68.8 & 68.0391 & 67.2118 & 67.2118 & \\
\hline 7344 & pín & .6533 & 69.6533 & 69.8540 & 70.0773 & 70.1312 & 69.9348 & 69.4369 & 68.5132 & & & \\
\hline 7427 & pì & 51 & 1.7851 & 71.5607 & 41 & 69.8616 & 68.2457 & 66.1 & 855 & & & \\
\hline 7452 & pí & 42 & 71.5142 & 71.1367 & .3484 & 69.4987 & 68.7181 & 68.3 & 575 & 68.6986 & 68.2807 & 67.4140 \\
\hline 7740 & pe & & 71.9921 & 71.9101 & 71.6631 & 71.3612 & 71.0547 & 70.68 & 70.1842 & 69.6297 & 69.0064 & 68.0656 \\
\hline 7992 & pá & 1554 & 67.1554 & 66.6923 & 65.8348 & 64.7684 & 63.4574 & 62.3107 & 61.6370 & 61.4320 & 61.1886 & 58.8585 \\
\hline 8172 & $\tilde{\mathbf{o}}$ & 8035 & 65.8035 & 65.8275 & 65.5996 & 65.1643 & 64.5976 & 63.9483 & 63.9483 & & & \\
\hline 8208 & $\ddot{\mathrm{o}}$ & 5748 & 67.5748 & 67.5441 & 67.4082 & 67.2674 & 67.1075 & 66.8804 & 66.5063 & 144 & 64.9516 & 64.3012 \\
\hline 8316 & ó & 9668 & 1.9668 & 72.3293 & 266 & 72.5673 & 72.4637 & 72.1 & & 70.7358 & 69.8660 & 69.3016 \\
\hline 8568 & $\mathrm{nu}$ & 230 & 5.1334 & 7.0756 & 67.7 & 68.3939 & 68.9164 & 69.6 & 901 & 70.9643 & 71.0570 & 71.0481 \\
\hline 8759 & nö & 5587 & 4.5587 & 65.0211 & 65.5692 & 66.6588 & 68.1045 & 68.7791 & 69.0113 & 69.0277 & 68.8341 & 68.5828 \\
\hline 8820 & nò & .3339 & 69.3339 & 70.1204 & 71.0390 & 71.7462 & 72.1483 & 72.3603 & 72.4674 & 72.5999 & 72.4758 & 72.0603 \\
\hline 9072 & ní & 0352 & 66.2922 & 67.5040 & 68.6034 & 69.7597 & 70.4559 & 70.7360 & 70.7707 & 70.6068 & 70.1952 & 69.5920 \\
\hline 9227 & në & 3580 & 67.3580 & 68.1681 & 69.0053 & 69.7971 & 70.9881 & 72.45 & 73.0856 & 72.9774 & 72.5072 & 71.8388 \\
\hline 9371 & ne & .0872 & 67.0872 & 67.3414 & 67.5814 & 67.9202 & 68.8308 & 70.14 & 70.8649 & 70.9370 & 70.6714 & 70.2189 \\
\hline 9587 & nà & .0359 & 66.0359 & 66.9357 & 67.5799 & 68.1733 & 68.8598 & 69.8327 & 70.4715 & 70.2825 & 69.2997 & 68.1224 \\
\hline 9659 & na & 9785 & 68.9785 & 70.2739 & 71.0969 & 71.2833 & 71.1675 & 70.9362 & 70.6058 & 70.0747 & 69.2323 & 68.2690 \\
\hline & $\mathrm{n}$ & & & & & & & & & & 66.4261 & 66.3211 \\
\hline 0152 & mô & 64.1690 & 64.1690 & 66.5050 & 67.9343 & 68.2302 & 68.2106 & 68.2462 & 68.2492 & 68.1524 & 67.9502 & 67.4341 \\
\hline
\end{tabular}

Table 4. Extracted Duration Features of Certain Syllables in Seconds

\begin{tabular}{|rcccccccccccc|}
\hline \multicolumn{1}{|c}{ Id } & S & $\mathbf{T 0}(\mathbf{d B})$ & $\mathbf{T 1}(\mathbf{d B})$ & $\mathbf{T 2}(\mathbf{d B})$ & $\mathbf{T 3}(\mathbf{d B})$ & $\mathbf{T 4}(\mathbf{d B})$ & $\mathbf{T 5}(\mathbf{d B})$ & $\mathbf{T 6}(\mathbf{d B})$ & $\mathbf{T 7}(\mathbf{d B})$ & $\mathbf{T 8}(\mathbf{d B})$ & $\mathbf{T 9}(\mathbf{d B})$ & $\mathbf{T 1 0}(\mathbf{d B})$ \\
\hline 36 & yún & 0.0202 & 0.0302 & 0.0402 & 0.0502 & 0.0602 & 0.0702 & 0.0802 & 0.0902 & 0.1002 & 0.1102 & 0.1202 \\
\hline 47 & yún & 0.0202 & 0.0302 & 0.0402 & 0.0502 & 0.0602 & 0.0702 & 0.0802 & 0.0902 & 0.1002 & 0.1102 & 0.1202 \\
\hline 72 & yun & 0.0227 & 0.0327 & 0.0427 & 0.0527 & 0.0627 & 0.0727 & 0.0827 & 0.0927 & 0.1027 & 0.1127 & 0.1227 \\
\hline 108 & yù & 0.0202 & 0.0302 & 0.0402 & 0.0502 & 0.0602 & 0.0702 & 0.0802 & 0.0902 & 0.1002 & 0.1102 & 0.1202 \\
\hline 119 & yù & 0.0202 & 0.0302 & 0.0402 & 0.0502 & 0.0602 & 0.0702 & 0.0802 & 0.0902 & 0.1002 & 0.1102 & 0.1202 \\
\hline 155 & yú & 0.0221 & 0.0321 & 0.0421 & 0.0521 & 0.0621 & 0.0721 & 0.0821 & 0.0921 & 0.1021 & 0.1121 & 0.1221 \\
\hline 828 & yë & 0.0231 & 0.0331 & 0.0431 & 0.0531 & 0.0631 & 0.0731 & 0.0831 & 0.0931 & 0.1031 & 0.1131 & 0.1231 \\
\hline 972 & ye & 0.0233 & 0.0333 & 0.0433 & 0.0533 & 0.0633 & 0.0733 & 0.0833 & 0.0933 & 0.1033 & 0.1133 & 0.1233 \\
\hline 1008 & yçn & 0.0202 & 0.0302 & 0.0402 & 0.0502 & 0.0602 & 0.0702 & 0.0802 & 0.0902 & 0.1002 & 0.1102 & 0.1202 \\
\hline 1019 & yçn & 0.0202 & 0.0302 & 0.0402 & 0.0502 & 0.0602 & 0.0702 & 0.0802 & 0.0902 & 0.1002 & 0.1102 & 0.1202 \\
\hline 2016 & wí & 0.0233 & 0.0333 & 0.0433 & 0.0533 & 0.0633 & 0.0733 & 0.0833 & 0.0933 & 0.1033 & 0.1133 & 0.1233 \\
\hline 2027 & wí & 0.0233 & 0.0333 & 0.0433 & 0.0533 & 0.0633 & 0.0733 & 0.0833 & 0.0933 & 0.1033 & 0.1133 & 0.1233 \\
\hline 2171 & wë & 0.0207 & 0.0307 & 0.0407 & 0.0507 & 0.0607 & 0.0707 & 0.0807 & 0.0907 & 0.1007 & 0.1107 & 0.1207 \\
\hline 2232 & wè & 0.0223 & 0.0323 & 0.0423 & 0.0523 & 0.0623 & 0.0723 & 0.0823 & 0.0923 & 0.1023 & 0.1123 & 0.1223 \\
\hline 2279 & wé & 0.0231 & 0.0331 & 0.0431 & 0.0531 & 0.0631 & 0.0731 & 0.0831 & 0.0931 & 0.1031 & 0.1131 & 0.1231 \\
\hline 2315 & we & 0.0234 & 0.0334 & 0.0434 & 0.0534 & 0.0634 & 0.0734 & 0.0834 & 0.0934 & 0.1034 & 0.1134 & 0.1234 \\
\hline 2376 & wç & 0.0218 & 0.0318 & 0.0418 & 0.0518 & 0.0618 & 0.0718 & 0.0818 & 0.0918 & 0.1018 & 0.1118 & 0.1218 \\
\hline 2772 & ù & 0.0200 & 0.0300 & 0.0400 & 0.0500 & 0.0600 & 0.0700 & 0.0800 & 0.0900 & 0.1000 & 0.1100 & 0.1200 \\
\hline
\end{tabular}




\begin{tabular}{|c|c|c|c|c|c|c|c|c|c|c|c|c|}
\hline 2808 & ú & 0.0249 & 0.0349 & 0.0449 & 0.0549 & 0.0649 & 0.0749 & 0.0849 & 0.0949 & 0.1049 & 0.1149 & 0.1249 \\
\hline 2819 & ú & 0.0249 & 0.0349 & 0.0449 & 0.0549 & 0.0649 & 0.0749 & 0.0849 & 0.0949 & 0.1049 & 0.1149 & 0.1249 \\
\hline 3024 & tu & 0.0248 & 0.0348 & 0.0448 & 0.0548 & 0.0648 & 0.0748 & 0.0848 & 0.0948 & 0.1048 & 0.1148 & 0.1248 \\
\hline 3215 & tö & 0.0207 & 0.0307 & 0.0407 & 0.0507 & 0.0607 & 0.0707 & 0.0807 & 0.0907 & 0.1007 & 0.1107 & 0.1207 \\
\hline 3240 & tô & 0.0235 & 0.0335 & 0.0435 & 0.0535 & 0.0635 & 0.0735 & 0.0835 & 0.0935 & 0.1035 & 0.1135 & 0.1235 \\
\hline 3312 & tó & 0.0227 & 0.0327 & 0.0427 & 0.0527 & 0.0627 & 0.0727 & 0.0827 & 0.0927 & 0.1027 & 0.1127 & 0.1227 \\
\hline 3575 & ti & 0.0230 & 0.0330 & 0.0430 & 0.0530 & 0.0630 & 0.0730 & 0.0830 & 0.0930 & 0.1030 & 0.1130 & 0.1230 \\
\hline 3827 & te & 0.0226 & 0.0326 & 0.0426 & 0.0526 & 0.0626 & 0.0726 & 0.0826 & 0.0926 & 0.1026 & 0.1126 & 0.1226 \\
\hline 4043 & tà & 0.0239 & 0.0339 & 0.0439 & 0.0539 & 0.0639 & 0.0739 & 0.0839 & 0.1339 & & & \\
\hline 4068 & tá & 0.0220 & 0.0320 & 0.0420 & 0.0520 & 0.0620 & 0.0720 & 0.0820 & 0.0920 & 0.1020 & 0.1120 & 0.1220 \\
\hline 4079 & tá & 0.0220 & 0.0320 & 0.0420 & 0.0520 & 0.0620 & 0.0720 & 0.0820 & 0.0920 & 0.1020 & 0.1120 & 0.1220 \\
\hline 4187 & sún & 0.0236 & 0.0336 & 0.0436 & 0.0536 & 0.0636 & 0.0736 & 0.0836 & 0.0936 & 0.1036 & 0.1136 & 0.1236 \\
\hline 4212 & sun & 0.0204 & 0.0304 & 0.0404 & 0.0504 & 0.0604 & 0.0704 & 0.0804 & 0.0904 & 0.1004 & 0.1104 & 0.1204 \\
\hline 4223 & sun & 0.0204 & 0.0304 & 0.0404 & 0.0504 & 0.0604 & 0.0704 & 0.0804 & 0.0904 & 0.1004 & 0.1104 & 0.1204 \\
\hline 4835 & sí & 0.0239 & 0.0339 & 0.0439 & 0.0539 & 0.0639 & 0.0739 & 0.0839 & 0.0939 & 0.1039 & 0.1139 & 0.1239 \\
\hline 5256 & sán & 0.0217 & 0.0317 & 0.0417 & 0.0517 & 0.0617 & 0.0717 & 0.0817 & 0.0917 & 0.1017 & 0.1117 & 0.1217 \\
\hline 5267 & sán & 0.0217 & 0.0317 & 0.0417 & 0.0517 & 0.0617 & 0.0717 & 0.0817 & 0.0917 & 0.1017 & 0.1117 & 0.1217 \\
\hline 5292 & san & 0.0230 & 0.0330 & 0.0430 & 0.0530 & 0.0630 & 0.0730 & 0.0830 & 0.0930 & 0.1030 & 0.1130 & 0.1230 \\
\hline 5483 & rún & 0.0210 & 0.0310 & 0.0410 & 0.0510 & 0.0610 & 0.0710 & 0.0810 & 0.0910 & 0.1010 & 0.1110 & 0.1210 \\
\hline 5591 & Rú & 0.0250 & 0.0350 & 0.0450 & 0.0550 & 0.0650 & 0.0750 & 0.0850 & 0.0950 & & & 0.1250 \\
\hline 5796 & Rö & 0.0242 & 0.0342 & 0.0442 & 0.0542 & 0.0642 & 0.0742 & 0.0842 & 0.0942 & 0.1042 & 0.1142 & 0.1242 \\
\hline 5807 & Rö & 0.0242 & 0.0342 & 0.0442 & 0.0542 & 0.0642 & 0.0742 & 0.0842 & 0.0942 & 0.1042 & 0.1142 & 0.1242 \\
\hline 5868 & Rò & 0.0243 & 0.0343 & 0.0443 & 0.0543 & 0.0643 & 0.0743 & 0.0843 & 0.0943 & 0.1043 & 0.1143 & 0.1243 \\
\hline 5904 & Ró & 0.0210 & 0.0310 & 0.0410 & 0.0510 & 0.0610 & 0.0710 & 0.0810 & 0.0910 & 0.1010 & 0.1110 & 0.1210 \\
\hline 6084 & Rì & 0.0203 & 0.0303 & 0.0403 & 0.0503 & 0.0603 & 0.0703 & 0.0803 & 0.0903 & 0.1003 & 0.1103 & 0.1203 \\
\hline 6131 & Rí & 0.0220 & 0.0320 & 0.0420 & 0.0520 & 0.0620 & 0.0720 & 0.0820 & 0.0920 & 0.1020 & 0.1120 & 0.1220 \\
\hline 6336 & Rê & 0.0228 & 0.0328 & 0.0428 & 0.0528 & 0.0628 & 0.0728 & 0.0828 & 0.0928 & 0.1028 & 0.1128 & 0.1228 \\
\hline 6347 & Rê & 0.0228 & 0.0328 & 0.0428 & 0.0528 & 0.0628 & 0.0728 & 0.0828 & 0.0928 & 0.1028 & 0.1128 & 0.1228 \\
\hline 6383 & Rè & 0.0245 & 0.0345 & 0.0445 & 0.0545 & 0.0645 & 0.0745 & 0.0845 & 0.0945 & 0.1045 & 0.1145 & 0.1245 \\
\hline 6444 & $\operatorname{Re}$ & 0.0201 & 0.0301 & 0.0401 & 0.0501 & 0.0601 & 0.0701 & 0.0801 & 0.0901 & 0.1001 & 0.1101 & 0.1201 \\
\hline 6588 & rán & 0.0226 & 0.0326 & 0.0426 & 0.0526 & 0.0626 & 0.0726 & 0.0826 & 0.0926 & 0.1026 & 0.1126 & 0.1226 \\
\hline 6948 & $\mathrm{Pu}$ & 0.0239 & 0.0339 & 0.0439 & 0.0539 & 0.0639 & 0.0739 & 0.0839 & 0.0939 & 0.1039 & 0.1139 & 0.1239 \\
\hline 6959 & $\mathrm{Pu}$ & 0.0239 & 0.0339 & 0.0439 & 0.0539 & 0.0639 & 0.0739 & 0.0839 & 0.0939 & 0.1039 & 0.1139 & 0.1239 \\
\hline 7020 & pön & 0.0201 & 0.0301 & 0.0401 & 0.0501 & 0.0601 & 0.0701 & 0.0801 & 0.0901 & 0.1001 & 0.1101 & 0.1201 \\
\hline 7031 & pön & 0.0201 & 0.0301 & 0.0401 & 0.0501 & 0.0601 & 0.0701 & 0.0801 & 0.0901 & 0.1001 & 0.1101 & 0.1201 \\
\hline 7128 & Pö & 0.0249 & 0.0349 & 0.0449 & 0.0549 & 0.0649 & 0.0749 & 0.0849 & 0.0949 & 0.1049 & 0.1149 & 0.1249 \\
\hline 7139 & Pö & 0.0249 & 0.0349 & 0.0449 & 0.0549 & 0.0649 & 0.0749 & 0.0849 & 0.0949 & 0.1049 & 0.1149 & 0.1249 \\
\hline 7175 & Pô & 0.0203 & 0.0303 & 0.0403 & 0.0503 & 0.0603 & 0.0703 & 0.0803 & 0.0903 & 0.1003 & 0.1103 & 0.1203 \\
\hline 7211 & Pò & 0.0217 & 0.0317 & 0.0417 & 0.0517 & 0.0617 & 0.0717 & 0.0817 & & & & \\
\hline 7272 & Po & 0.0228 & 0.0328 & 0.0428 & 0.0528 & 0.0628 & 0.0728 & 0.0828 & 0.0928 & 0.1028 & 0.1128 & \\
\hline 7344 & pín & 0.0201 & 0.0301 & 0.0401 & 0.0501 & 0.0601 & 0.0701 & 0.0801 & 0.0901 & 0.1001 & 0.1101 & 0.1201 \\
\hline 7427 & Pì & 0.0204 & 0.0304 & 0.0404 & 0.0504 & 0.0604 & 0.0704 & 0.0804 & 0.0904 & & & \\
\hline 7452 & Pí & 0.0242 & 0.0342 & 0.0442 & 0.0542 & 0.0642 & 0.0742 & 0.0842 & 0.0942 & 0.1042 & 0.1142 & 0.1242 \\
\hline 7740 & $\mathrm{Pe}$ & 0.0249 & 0.0349 & 0.0449 & 0.0549 & 0.0649 & 0.0749 & 0.0849 & 0.0949 & 0.1049 & 0.1149 & 0.1249 \\
\hline 7992 & Pá & 0.0227 & 0.0327 & 0.0427 & 0.0527 & 0.0627 & 0.0727 & 0.0827 & 0.0927 & 0.1027 & 0.1127 & 0.1227 \\
\hline 8172 & $\tilde{O}$ & 0.0246 & 0.0346 & 0.0446 & 0.0546 & 0.0646 & 0.0746 & 0.0846 & 0.0946 & & & \\
\hline 8208 & $\ddot{O}$ & 0.0202 & 0.0302 & 0.0402 & 0.0502 & 0.0602 & 0.0702 & 0.0802 & 0.0902 & 0.1002 & 0.1102 & 0.1202 \\
\hline 8316 & Ó & 0.0223 & 0.0323 & 0.0423 & 0.0523 & 0.0623 & 0.0723 & 0.0823 & 0.0923 & 0.1023 & 0.1123 & 0.1223 \\
\hline
\end{tabular}




\begin{tabular}{|ccccccccccccc|}
8568 & $\mathrm{Nu}$ & 0.0246 & 0.0346 & 0.0446 & 0.0546 & 0.0646 & 0.0746 & 0.0846 & 0.0946 & 0.1046 & 0.1146 & 0.1246 \\
\hline 8759 & $\mathrm{Nö}$ & 0.0248 & 0.0348 & 0.0448 & 0.0548 & 0.0648 & 0.0748 & 0.0848 & 0.0948 & 0.1048 & 0.1148 & 0.1248 \\
\hline 8820 & Nò & 0.0206 & 0.0306 & 0.0406 & 0.0506 & 0.0606 & 0.0706 & 0.0806 & 0.0906 & 0.1006 & 0.1106 & 0.1206 \\
\hline 9072 & Ní & 0.0249 & 0.0349 & 0.0449 & 0.0549 & 0.0649 & 0.0749 & 0.0849 & 0.0949 & 0.1049 & 0.1149 & 0.1249 \\
\hline 9227 & $\mathrm{Në}$ & 0.0233 & 0.0333 & 0.0433 & 0.0533 & 0.0633 & 0.0733 & 0.0833 & 0.0933 & 0.1033 & 0.1133 & 0.1233 \\
\hline 9371 & $\mathrm{Ne}$ & 0.0211 & 0.0311 & 0.0411 & 0.0511 & 0.0611 & 0.0711 & 0.0811 & 0.0911 & 0.1011 & 0.1111 & 0.1211 \\
\hline 9587 & $\mathrm{Nà}$ & 0.0245 & 0.0345 & 0.0445 & 0.0545 & 0.0645 & 0.0745 & 0.0845 & 0.0945 & 0.1045 & 0.1145 & 0.1245 \\
\hline 9659 & $\mathrm{Na}$ & 0.0235 & 0.0335 & 0.0435 & 0.0535 & 0.0635 & 0.0735 & 0.0835 & 0.0935 & 0.1035 & 0.1135 & 0.1235 \\
\hline 9720 & $\mathrm{~N}$ & 0.0213 & 0.0313 & 0.0413 & 0.0513 & 0.0613 & 0.0713 & 0.0813 & 0.0913 & 0.1013 & 0.1113 & 0.1213 \\
\hline 10152 & mô & 0.0235 & 0.0335 & 0.0435 & 0.0535 & 0.0635 & 0.0735 & 0.0835 & 0.0935 & 0.1035 & 0.1135 & 0.1235 \\
\hline
\end{tabular}

Table 5. Mean Values for Extracted Features of Syllables

\begin{tabular}{|c|c|c|c|c|c|c|c|c|c|}
\hline Id & $\mathbf{S}$ & NF & $\mathbf{S P}(\mathbf{s})$ & D (s) & MPC (Hz) & MPP (Hz) & SDPC & SDPP & $\operatorname{ETP}(\mathbf{s})$ \\
\hline 36 & yún & 26 & 0.0000 & 0.2904 & 152.0796 & 152.0100 & 43.8074 & 27.4252 & 0.2904 \\
\hline 47 & yún & 25 & 0.0000 & 0.2904 & 143.6029 & 144.8873 & 61.9963 & 48.7294 & 0.2904 \\
\hline 72 & yun & 29 & 0.0000 & 0.3253 & 121.6787 & 122.0979 & 27.4586 & 10.6191 & 0.3253 \\
\hline 108 & yù & 16 & 0.0000 & 0.1903 & 99.2542 & 99.4725 & 25.9855 & 2.0512 & 0.1903 \\
\hline 119 & yù & 11 & 0.0000 & 0.1903 & 99.3778 & 107.1205 & 42.4009 & 22.1473 & 0.1903 \\
\hline 155 & yú & 27 & 0.0000 & 0.3142 & 140.2745 & 141.7953 & 55.6729 & 41.4099 & 0.3142 \\
\hline 828 & yë & 25 & 0.0000 & 0.2861 & 132.7996 & 132.8151 & 40.5266 & 25.0702 & 0.2861 \\
\hline 972 & ye & 33 & 0.0000 & 0.3667 & 110.6201 & 110.6526 & 26.3368 & 13.0177 & 0.3667 \\
\hline 1008 & yçn & 30 & 0.0000 & 0.3304 & 110.5507 & 110.7147 & 24.1665 & 9.8441 & 0.3304 \\
\hline 1019 & yçn & 23 & 0.0000 & 0.3304 & 130.5383 & 137.0289 & 55.5117 & 42.7529 & 0.3304 \\
\hline 2016 & wí & 18 & 0.0000 & 0.2165 & 167.1898 & 167.1921 & 56.4727 & 31.8892 & 0.2165 \\
\hline 2027 & wí & 18 & 0.0000 & 0.2165 & 149.4088 & 149.9393 & 49.0773 & 27.6795 & 0.2165 \\
\hline 2171 & wë & 21 & 0.0000 & 0.2515 & 132.3561 & 134.2253 & 45.6280 & 30.1191 & 0.2515 \\
\hline 2232 & wè & 20 & 0.0000 & 0.2346 & 97.2361 & 98.6374 & 22.0786 & 5.8115 & 0.2346 \\
\hline 2279 & wé & 22 & 0.0000 & & 127.3490 & & 46.5140 & 32.0518 & 0.2563 \\
\hline 2315 & we & 16 & 0.0000 & 0.2368 & 115.6685 & 123.8763 & 48.8091 & 32.1188 & 0.2368 \\
\hline 2376 & wç & 20 & 0.0000 & 0.2337 & 115.4044 & 115.4662 & 29.8982 & 7.6477 & 0.2337 \\
\hline 2772 & ù & 18 & 0.0000 & 0.2101 & & & 22.7850 & 5.0952 & 0.2101 \\
\hline 2808 & ú & 19 & 0.0000 & 0.2297 & 182.1944 & 181.1096 & 59.3558 & 26.3641 & 0.2297 \\
\hline 2819 & ú & 19 & 0.0000 & 0.2297 & 167.8146 & 166.6569 & 65.2970 & 42.0648 & 0.2297 \\
\hline 3024 & tu & 15 & 0.0000 & 0.1896 & 119.5114 & 119.7731 & 34.9410 & 2.0615 & 0.1896 \\
\hline 3215 & tö & 15 & 0.0000 & 0.1814 & 142.9495 & 141.5081 & 54.5402 & 31.5861 & 0.1814 \\
\hline 3240 & tô & 17 & 0.0000 & 0.2070 & 113.7873 & 112.7797 & 33.7060 & 4.9464 & 0.2070 \\
\hline 3312 & tó & 13 & 0.0000 & 0.1654 & 166.3811 & 164.9713 & 55.7977 & 16.7820 & 0.1654 \\
\hline 3575 & $\mathrm{ti}$ & 17 & & & 122.3120 & 123.4541 & 53.0796 & 36.3502 & 0.2160 \\
\hline 3827 & te & 15 & 0.0000 & 0.1851 & 126.2890 & 124.3567 & 54.2306 & 33.6969 & 0.1851 \\
\hline 4043 & tà & 8 & 0.0000 & 0.1577 & 100.2770 & 106.1232 & 44.2988 & 23.4288 & 0.1577 \\
\hline 4068 & tá & 16 & 0.0000 & & 153.5096 & 152.9872 & 45.4450 & 13.1749 & 0.1939 \\
\hline 4079 & tá & 16 & 0.0000 & 0.1939 & 143.2690 & 141.8769 & 56.5377 & 34.2700 & 0.1939 \\
\hline 4187 & sún & 15 & 0.0000 & 0.1873 & 174.8550 & 173.3948 & 64.3995 & 32.7395 & 0.1873 \\
\hline 4212 & sun & 18 & & & & & 36.3782 & & 0.2109 \\
\hline 4223 & sun & 17 & 0.0000 & 0.2109 & 131.3698 & 132.1017 & 57.8670 & 39.5015 & 0.2109 \\
\hline 4835 & sí & 15 & 0.0000 & 0.1877 & 169.8467 & 169.4228 & 59.5798 & 29.7671 & 0.1877 \\
\hline 5256 & sán & 14 & 0.0000 & & & 153.4527 & 50.0988 & 16.3825 & 0.1734 \\
\hline 5267 & sán & 14 & 0.0000 & 0.1734 & 141.0734 & 139.9134 & 51.4278 & 26.1309 & 0.1734 \\
\hline 5292 & $\operatorname{san}$ & 19 & 0.0000 & 0.2260 & 108.8811 & 108.2577 & 30.2288 & 5.6276 & 0.2260 \\
\hline 5483 & rún & 21 & 0.0000 & & & 133.3840 & 50.6419 & 35.3982 & 0.2420 \\
\hline 5591 & rú & 18 & 0.0000 & 0.2199 & 135.2542 & 134.8845 & 46.3850 & 24.6042 & 0.2199 \\
\hline 5796 & rö & 25 & 0.0000 & 0.2884 & 138.8990 & 138.6745 & 42.4067 & 24.6587 & 0.2884 \\
\hline 5807 & rö & 23 & 0.0000 & 0.2884 & 131.3259 & 134.1779 & 56.4954 & 40.2940 & 0.2884 \\
\hline 5868 & rò & 15 & 0.0000 & 0.1885 & 90.0719 & 90.4470 & 26.3164 & 5.1720 & 0.1885 \\
\hline
\end{tabular}




\begin{tabular}{|c|c|c|c|c|c|c|c|c|c|}
\hline 5904 & ró & 20 & 0.0000 & 0.2320 & 150.6295 & 150.5199 & 43.9947 & 21.1128 & 0.2320 \\
\hline 6084 & rì & 19 & 0.0000 & 0.2207 & 94.0946 & 94.9447 & 21.6892 & 4.0459 & 0.2207 \\
\hline 6131 & rí & 24 & 0.0000 & 0.2740 & 135.2617 & 135.0051 & 51.6648 & 37.8659 & 0.2740 \\
\hline 6336 & rê & 16 & 0.0000 & 0.2156 & 91.3141 & 93.6679 & 23.7614 & 7.6764 & 0.2156 \\
\hline 6347 & rê & 11 & 0.0000 & 0.2156 & 102.7262 & 115.2829 & 45.5482 & 23.6329 & 0.2156 \\
\hline 6383 & rè & 17 & 0.0000 & 0.2690 & 113.0376 & 120.0446 & 48.7815 & 32.9268 & 0.2690 \\
\hline 6444 & re & 22 & 0.0000 & 0.2502 & 118.7393 & 119.1509 & 27.7281 & 7.6425 & 0.2502 \\
\hline 6588 & rán & 23 & 0.0000 & 0.2652 & 138.9822 & 139.4407 & 39.2851 & 21.3245 & 0.2652 \\
\hline 6948 & $\mathrm{pu}$ & 15 & 0.0000 & 0.1879 & 124.8141 & 124.1181 & 37.9155 & 4.0678 & 0.1879 \\
\hline 6959 & $\mathrm{pu}$ & 15 & 0.0000 & 0.1879 & 118.7901 & 117.0187 & 51.8350 & 32.5769 & 0.1879 \\
\hline 7020 & pön & 15 & 0.0000 & 0.1801 & 159.6729 & & 47.0880 & 17.7541 & 0.1801 \\
\hline 7031 & pön & 15 & 0.0000 & 0.1801 & 146.6533 & 146.1834 & 51.4669 & 28.2446 & 0.1801 \\
\hline 7128 & pö & 16 & 0.0000 & 0.1997 & 164.5208 & 163.4983 & 58.1787 & 30.0853 & 0.1997 \\
\hline 7139 & Pö & 16 & 0.0000 & 0.1997 & 148.1998 & 147.1462 & 52.3768 & 24.0293 & 0.1997 \\
\hline 7175 & Pô & 15 & 0.0000 & 0.1906 & 117.6896 & 118.7303 & 47.7518 & 30.5091 & 0.1906 \\
\hline 7211 & Pò & 7 & 0.0000 & 0.1233 & 109.2265 & 113.9491 & 48.1976 & 20.7002 & 0.1233 \\
\hline 7272 & Po & 10 & 0.0000 & 0.1 & 123.8407 & 123.8047 & 41.5913 & 2.5611 & 0.1356 \\
\hline 7344 & Pín & 14 & 0.0000 & 0.1702 & 164.3554 & 164.1827 & 50.3244 & 18.4331 & 0.1702 \\
\hline 7427 & Pì & 8 & 0.0000 & 0.1308 & 105.2972 & 109.8747 & 46.5141 & 24.2064 & 0.1308 \\
\hline 7452 & Pí & 15 & 0.0000 & 0.1884 & 182.3439 & 183.3684 & 58.6645 & 26.7084 & 0.1884 \\
\hline 7740 & $\mathrm{Pe}$ & 17 & 0.0000 & 0.2099 & 132.2 & 132.1263 & 38.3 & 7.5802 & 0.2099 \\
\hline 7992 & Pá & 13 & 0.0000 & 0.1655 & 150.5219 & 149.8611 & 52.0357 & 22.5772 & 0.1655 \\
\hline 8172 & $\tilde{\mathrm{O}}$ & 8 & 0.0000 & 0.1191 & 99.4116 & 99.6973 & 36.6573 & 2.8550 & 0.1191 \\
\hline 8208 & Ö & 19 & 0.0000 & 0.2204 & 163.6149 & 163.6402 & 48.6906 & 26.2607 & 0.2204 \\
\hline 8316 & Ó & 18 & 0.0000 & 0.2246 & 129.1719 & 131.5997 & 36.4759 & 25.8920 & 0.2246 \\
\hline 8568 & $\mathrm{Nu}$ & 25 & 0.0000 & 0.2891 & 140.5224 & 141.6423 & 33.4255 & 12.1187 & 0.2891 \\
\hline 8759 & Nö & 20 & 0.0000 & 0.2395 & 141.3034 & 140.9247 & 47.2002 & 26.1045 & 0.2395 \\
\hline 8820 & Nò & 18 & 0.0000 & 0.2112 & 102.6451 & 103.7473 & 24.5550 & 6.3203 & 0.2112 \\
\hline 9072 & Ní & 17 & 0.0000 & 0.2099 & 171.1889 & 170.6888 & 59.9074 & 31.1589 & 0.2099 \\
\hline 9227 & $\mathrm{Në}$ & 21 & 0.0000 & 0.2466 & 158.6528 & 158.0243 & 56.0524 & 35.1576 & 0.2466 \\
\hline 9371 & $\mathrm{Ne}$ & 18 & 0.0000 & 0.2522 & 125.0962 & 133.6226 & 55.4558 & 40.6220 & 0.2522 \\
\hline 9587 & Nà & 13 & 0.0000 & 0.2289 & 118.2873 & 133.3755 & 56.5511 & 37.4787 & 0.2289 \\
\hline 9659 & $\mathrm{Na}$ & 16 & 0.0000 & & 129.6426 & 140.4555 & 57.5689 & 40.2845 & 0.2370 \\
\hline 9720 & $\mathrm{~N}$ & 27 & 0.0000 & 0.3026 & 140.1785 & 140.1660 & 31.7942 & 8.1726 & 0.3026 \\
\hline 10152 & Mô & 19 & 0.0000 & 0.2271 & 108.4655 & 107.6228 & 30.4556 & 3.4576 & 0.2271 \\
\hline
\end{tabular}

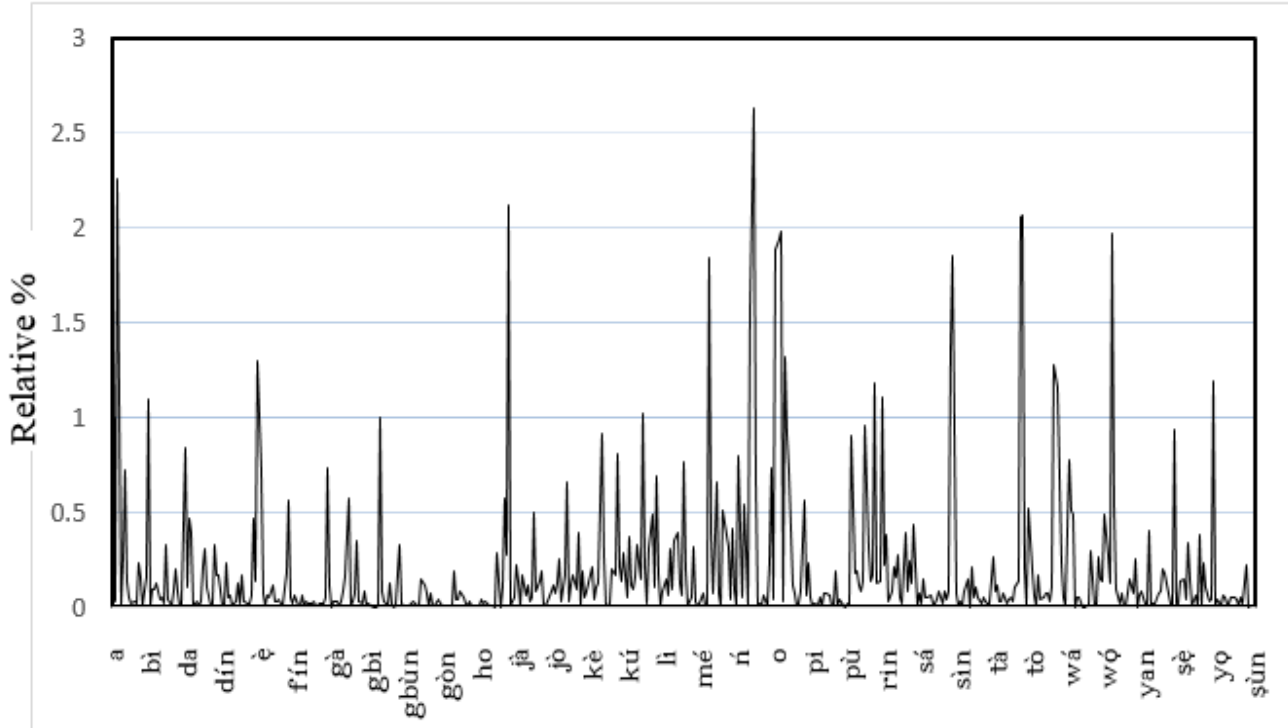

Figure 12: Relative \% of Corporal Syllables in Selection (Alphabetic order) 


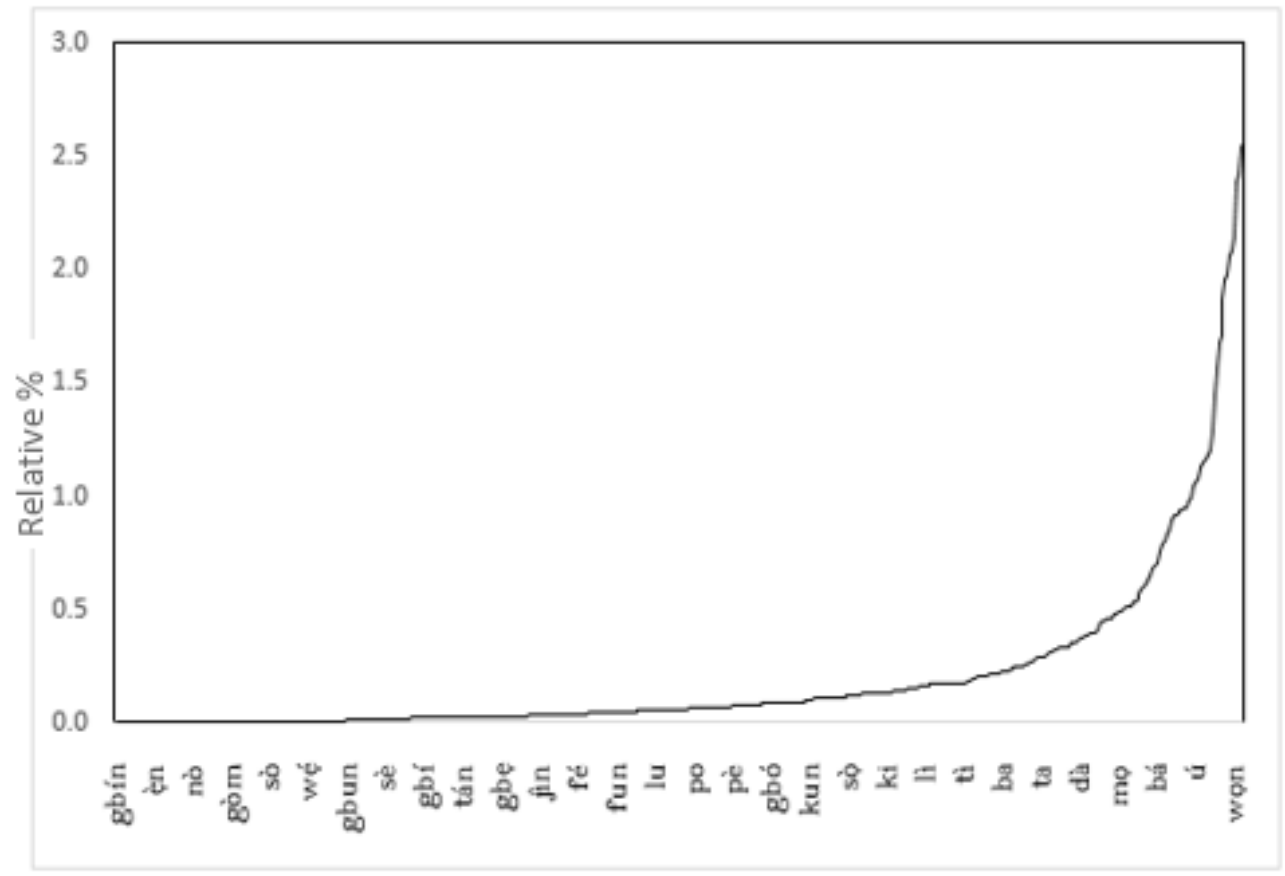

Figure 13: Relative \% of Corporal Syllables in Selection (Ascending order)

\section{SYSTEM EVALUATION}

\subsection{Mean Opinion Score (MOS)}

The developed corpus was used to run a Standard Yoruba Text-to-Speech system. A mean opinion score was computed for the perceived overall quality of the systemstimuli. This measured the speech naturalness component of prosody. The MOS was estimated as an arithmetic mean for all individual.

30 Selected listeners were played some speech generated with the database and asked to rate what they perceived. The Listeners were told to indicate their assessments on a scale of 1 to 5 . The grading is shown on Table 6 .

Table 6. Rating and Grading Used for MOSTest

\begin{tabular}{|c|c|}
\hline Rating & Grade \\
\hline 5 & Excellent \\
\hline 4 & Good \\
\hline 3 & Fair \\
\hline 2 & Poor \\
\hline 1 & Bad \\
\hline
\end{tabular}

\subsection{Semantically Unpredictable Sentences}

\section{(SUS) Test}

Intelligibility test of the corpus was carried out by usingthe semantically unpredictable sentences to estimate the quality of speech produced by the Standard Yoruba Text-to-Speech system using the corpus. The gave a measure of word recognition. In semantically unpredictable sentences (SUS) test, a subject in a quiet room listens to a series of 90 short semantically unpredictable (nonsense) sentences over loudspeakers. Some of the sentences were difficult to understand. The subject heard each sentence once, then he rated the intelligibility of the sentence on a scale from $1-7$.
Naturalness and Intelligibility tests were performed to estimate the quality of speech produced bythe Standard Yoruba Text-to-Speech system using the corpus. mean opinion score and semantically unpredictable sentences (SUS) test conducted with 30 subjects who understand and use SY regularly. The following results were obtained from 30 subjects. Table 7 shows the Rating and Grading Used for SUS Test while Table 8 presents the Result of SUS Test.

Table 7. Rating and Grading Used for SUSTest

\begin{tabular}{|c|c|}
\hline Rating & Grade \\
\hline 7 & Ideal \\
\hline 6 & Excellent \\
\hline 5 & Good \\
\hline 4 & Fair \\
\hline 3 & Poor \\
\hline 2 & Bad \\
\hline 1 & $\begin{array}{c}\text { Extremely } \\
\text { Bad }\end{array}$ \\
\hline
\end{tabular}


Table 8. Result of SUS Test

\begin{tabular}{|c|c|c|c|c|c|}
\hline Z & 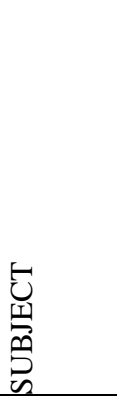 & 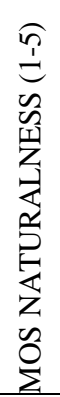 & 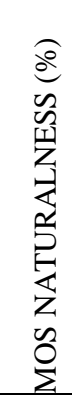 & 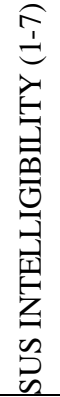 & 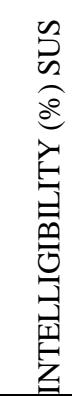 \\
\hline 1 & Subj1 & 3 & 60 & 6 & 85.7 \\
\hline 2 & Subj2 & 4 & 80 & 6 & 85.7 \\
\hline 3 & Subj3 & 2 & 40 & 7 & 100 \\
\hline 4 & Subj4 & 4 & 80 & 6 & 85.7 \\
\hline 5 & Subj5 & 4 & 80 & 7 & 100 \\
\hline 6 & Subj6 & 4 & 80 & 6 & 85.7 \\
\hline 7 & Subj7 & 4 & 80 & 7 & 100 \\
\hline 8 & Subj8 & 4 & 80 & 6 & 85.7 \\
\hline 9 & Subj9 & 4 & 80 & 6 & 85.7 \\
\hline 10 & Subj10 & 3 & 60 & 7 & 100 \\
\hline 11 & Subj11 & 4 & 80 & 7 & 100 \\
\hline 12 & Subj12 & 3 & 60 & 7 & 100 \\
\hline 13 & Subj13 & 4 & 80 & 6 & 85.7 \\
\hline 14 & Subj14 & 3 & 60 & 6 & 85.7 \\
\hline 15 & Subj15 & 4 & 80 & 7 & 100 \\
\hline 16 & Subj16 & 4 & 80 & 7 & 100 \\
\hline 17 & Subj17 & 2 & 40 & 7 & 100 \\
\hline 18 & Subj18 & 4 & 80 & 6 & 85.7 \\
\hline 19 & Subj19 & 3 & 60 & 6 & 85.7 \\
\hline 20 & Subj20 & 4 & 80 & 6 & 85.7 \\
\hline 21 & Subj21 & 4 & 80 & 7 & 100 \\
\hline 22 & Subj22 & 4 & 80 & 6 & 85.7 \\
\hline 23 & Subj23 & 4 & 80 & 7 & 100 \\
\hline 24 & Subj24 & 3 & 60 & 7 & 100 \\
\hline 25 & Subj25 & 4 & 80 & 6 & 85.7 \\
\hline 26 & Subj26 & 4 & 80 & 7 & 100 \\
\hline 27 & Subj27 & 3 & 60 & 7 & 100 \\
\hline 28 & Subj28 & 4 & 80 & 7 & 100 \\
\hline 29 & Subj29 & 4 & 80 & 7 & 100 \\
\hline 30 & Subj30 & 4 & 80 & 6 & 85.7 \\
\hline \multicolumn{2}{|c|}{$\begin{array}{l}\text { Arithmetic } \\
\text { Mean }\end{array}$} & 3.6 & 72.7 & 6.5 & 93.3 \\
\hline
\end{tabular}

Intelligibility test is carried out with the modified rhyme test or semantically unpredictable sentences. These give a measure of word recognition. In semantically unpredictable sentences (SUS) test, a subject in a quiet room listens to a series of 90 short semantically unpredictable (nonsense) sentences over loudspeakers. Some of the sentences may be difficult to understand. The subject hears each sentence once, then he rates the intelligibility of the sentence on a scale from $1-7$.

Naturalness and Intelligibility tests were performed to estimate the perceptive quality of ProTToSSYL speech by way of mean opinion score and semantically unpredictable sentences (SUS) test conducted with 30 subjects who understand and use SY regularly. The following results were obtained from 30 subjects.

These tests show that the corpus produced a synthetic speech of $\mathrm{MOS}=3.6(72.7 \%)$ naturalness and SUS Score $=6.5$ $(93.3 \%)$ intelligibility.

\section{CONCLUSION}

This research developed a prosodic read corpus for the Standard Yoruba languageby extracting textual inputs from four sources: two Standard Yoruba (SY) fiction, an SY grammar textbook and an SY Online Scripture. The author applied a hybrid of Falaschi scheme and the add-on procedure of Radová and Vopálka to obtain phonetically balanced text bag containing 7376 phrases and sentences. The selected text was carefully read by an expert and recorded in a suitable environment and saved as wave files. The wave files were annotated with Praat. The relational database developed hosts the corpus metadata.

The corpus performed impressively when tested with a Standard Yoruba TTS.72.7\% naturalness and 93.3\% intelligibility were recorded.

Yoruba Language is tonal, exhibiting a tonality of 3. The tonality is not fixed. By implication, the syllables havesurface tones which are usually pitched at relatively dissimilar perceptual frequency levels. The syllable is a natural and convenient base unit for speech in Yoruba Language. Thus, the corpus is syllable based.

The result shows a naturalness of $72.7 \%$ when the corpus was used with a TTS. It is believed that limitation could have arose from perhaps miss syllabification of words in the corpus, and or absence of prosodic representation in written text. Error of syllabification could have arisen from the factthat the syllabification algorithm used a Declarative RulesBased Approach (DRSA) for the syllabification of SY words. The DRSA would fail to completely disambiguate all the CV.N and DV.N syllabic structures. Consequently, it would misidentify some of the $/ \mathrm{n} /$ variant of the CV.N and DV.N syllable structures. Hence there is need to improve upon the syllabification algorithm used.

Moreover, if larger number of sentences were used, there could have been a wider coverage of the prosodic space than was is observed with 7376 phrases and sentences.

This study has been able to contribute a speech corpus to the Standard Yoruba NLP research.

\section{REFERENCES}

[1] Atoye R. O. 1999. "Native -Speaker Perception of Intonation in Yoruba Zero- Particle Interrogative Clauses." Papers in English and Linguistics 4:15 - 23, 1999.

[2] Ajolore O. 1974. Learning to Use Yorùbá focus sentence in a multilingual setting. Ph.D. Thesis, University of 
Ilinouis, USA, 1974.

[3] Adetugbo A. 1973. The Yoruba Language in Yoruba History. in Biobaku, S.O. (ed.). Sources of Yoruba History. pp. 176-204.

[4] Crowther S. 1843. Vocabulary of the Yorùbá Language... to which are prefixed the grammatical elements of the Yoruba language. Church Missionary Society, London.

[5] Fagborun J. G. 1994. The Yoruba Koiné - its History and Linguistic Innovations. LINCOM Linguistic Edition Vol. 6. München/Newcastle: LINCOM Europe.

[6] Akinlabi A. and Liberman M. 2000. The tonal phonology of Yoruba clitics. Rutgers Univ. \& Univ. of Pennsylvania.

[7] Adewole L. O. 1987. The Yoruba Language: Published works and doctoral dissertations, 1843 - 1986. Hamburg: Helmut Buske.

[8] Taylor, P. 2009. Text-to-speech synthesis. Cambridge, UK: Cambridge University Press. pp. 3.

[9] Fajobi E. 2003. Why does Yoruba high tone fall where it does in 'Yorubalized' English words?" In Kingsley Sage (ed.). The 16th White House Papers: Graduate Research in Cognitive and Computing Sciences at Sussex. pp.34 36.

[10] Beckman, M.E., 1996. The parsing of prosody. Language and cognitive processes, 11(1-2), pp.17-68.

[11] Wennerstrom A. K.2001. The music of everyday speech: Prosody and discourse analysis. Oxford: Oxford University Press, 2001.

[12] Bird, S. 2011. Strategies for representing tone in African writing systems: a critical review. URL:http://cogprints.org/2174/00/wll2.pdf. (Access date: 7 July 2011).

[13] Oyetade B. A. 1987. Tone representation and Yoruba tone. Paper presented at UCL Dept. of Phonetics and Linguistics Postgraduate Seminar in March, 1987 and the Spring Meeting of the LAGB, Westfield College,
London, April.

[14] Hu, C. 2003. Text statistics tool box for natural language processing. Technical report, The University of Georgia, May.

[15] Ngugi, K., Okelo-Odongo, W. and Wagacha, P.W., 2005. Swahili text-to-speech system. African Journal of Science and Technology, 6(1).

[16] Onayemi A. O. 2010, "Learn Yoruba", http://www.learnyoruba.com/ aboutus.htm. Retrieved on June 20, 2021

[17] Akinwonmi, A. E. and Alese, B. K. 2013. A prosodic text-to-speech system for the Yorùbá language. The 8th International Conference for Internet Technology and Secured Transactions (ICITST-2013). Technically Cosponsored by IEEE UK/RI Computer Chapter. December 9-12, 2013, in London, UK. Pages $634-639$ of the Conference Proceedings. ISBN 978-1-908320-16-2.

[18] Adedjouma Sèmiyou, A., Aoga, J.O. and Igue, M.A., 2012. Part-of-Speech tagging of Yorùbá Standard, Language of Niger-Congo family. Research Journal of Computer and Information Technology Sciences. Vol. 1 pages 2-5.

[19] Olaniyan, O. L. 2015. Development of a Yoruba Language Syllabificator. (Postgraduate diploma dissertation). The Federal University of Technology, Akure, Ondo State. Nigeria.

[20] Agrawal, S. S., Samudravijaya, K. and Arora, K. 2006. Recent advances of speech databases development activity for Indian languages, In Proc. ISCSLP 2006, Singapore, pp. 771-776.

[21] Kumolalo, F. O., Adagunodo, E. R., and Odejobi, O. A. 2010. Development of a Syllabicator for Yoruba Language. In Proceedings of OAU TekConf, September 5-8, 2010, pages 47-51, OAU, Ile-Ife, Nigeria.

[22] Broder, A.Z., Glassman, S.C., Manasse, M.S. and Zweig, G., 1997. Syntactic clustering of the web. Computer networks and ISDN systems, 29(8-13), pp.1157-1166. 